\title{
Asimetrías estructurales y crisis sanitaria: el imperativo de una recuperación transformadora para el desarrollo sostenible en América Latina y el Caribe ${ }^{1}$
}

\author{
Alicia Bárcena y Mario Cimoli
}

\section{Resumen}

En este artículo se plantea la urgencia de avanzar hacia un nuevo modelo de desarrollo en América Latina y el Caribe ante la crisis sanitaria actual. Las estadísticas indican que la región ha sido la más afectada por la pandemia y también la más dañada en términos económicos y sociales. Esto se debe a factores estructurales de larga data que han prefigurado su disfuncional estilo de desarrollo. La región creció a un exiguo 0,4\% anual entre 2014 y 2019, en un contexto de profundización de la brecha de productividad externa, heterogeneidad estructural, senderos de baja productividad y un progresivo descenso de la participación de la masa salarial en el producto. Ello ha derivado también en un retroceso en el proceso de desarrollo socioeconómico. Así, la reactivación económica deberá cursar, a la par, significativas reformas estructurales productivas, fiscales e institucionales, para avanzar en la configuración de un estilo de desarrollo inclusivo y sostenible.

\section{Palabras clave}

COVID-19, virus, epidemias, aspectos económicos, crisis económica, salud, pobreza, desempleo, crecimiento económico, producto interno bruto, distribución del ingreso

Clasificación JEL

O54, D30, G01, 114

\section{Autores}

Alicia Bárcena es Secretaria Ejecutiva de la Comisión Económica para América Latina y el Caribe (CEPAL). Correo electrónico: alicia.barcena@un.org.

Mario Cimoli es Secretario Ejecutivo Adjunto de la Comisión Económica para América Latina y el Caribe (CEPAL). Correo electrónico: mario.cimoli@un.org.

\footnotetext{
Los autores agradecen los comentarios y aportes al texto de Gabriel Porcile, Vianka Aliaga y Cecilia Vera, y la colaboración de Claudio Aravena, Pablo Carvallo, Ernesto Espíndola, Nicole Favreau y Fernando Sossdorf, quienes suministraron diversos insumos cuantitativos que nutren la argumentación de este artículo.
} 


\section{Introducción}

La propagación de la enfermedad por coronavirus (COVID-19) en América Latina y el Caribe a partir de marzo de 2020 ha desatado no solo una grave emergencia sanitaria en nuestros países, materializándose en una significativa pérdida de vidas humanas, sino que, además, ha tenido graves efectos económicos y sociales. Estos efectos, a su vez, han tenido como consecuencia mayor la de reforzar el sesgo recesivo en términos de menores tasas de crecimiento, dinamismo exportador, inversión productiva y empleo, que ya venían enfrentando las economías regionales antes de la crisis sanitaria. Dicho sesgo recesivo ha dado paso en varios casos a un proceso de estancamiento económico, y ha estado acompañado consecuentemente de retrocesos significativos en materia social, como el aumento del número de personas en situación de pobreza y el empeoramiento de la distribución del ingreso (tanto en términos factoriales como personales). En este contexto, en algunos países la crisis socioeconómica ha devenido también en profundas crisis políticas, poniendo en riesgo la democracia y la amplia inclusión social que requiere todo proceso virtuoso de desarrollo.

Frente a la irrupción del COVID-19 y sus efectos, aún en curso, la Comisión Económica para América Latina y el Caribe (CEPAL) ha desplegado desde marzo un gran esfuerzo de análisis de los alcances sanitarios, sociales y económicos de esta crisis, ofreciendo a los países miembros propuestas de políticas para reactivar la economía regional y retomar así una nueva senda de crecimiento y desarrollo sostenibles.

En este artículo se analizan los factores estructurales que explican por qué esta crisis pandémica ha tenido mayor incidencia sanitaria y socioeconómica en América Latina y el Caribe que en las demás regiones del mundo y se revisa la producción intelectual de la CEPAL en torno a la crisis sanitaria. Se argumenta que debido a esos factores estructurales el estilo de desarrollo anterior a la pandemia era insostenible desde el punto de vista social (desigualdad), económico (persistencia de asimetrías productivas y tecnológicas con los países avanzados) y ambiental (superación de los límites planetarios en el uso de los recursos naturales y la biosfera). Estos tres factores deben ser analizados de forma integrada, tomando en cuenta sus múltiples mecanismos de interacción. Este abordaje integrado se hace a partir de un modelo analítico de tres brechas (la económica, la social y la ambiental), propuesto por la CEPAL en el documento presentado en su trigésimo octavo período de sesiones (CEPAL, 2020i), en el que se describen el patrón actual de crecimiento y las perspectivas de avance hacia uno más virtuoso.

El artículo consta de seis secciones. En la sección II se analizan los alcances globales de la pandemia en términos de incidencia sanitaria y sus efectos económicos. En la sección III se explican los hechos estilizados que caracterizan la dinámica económica de la región antes de que se produjera la crisis sanitaria. En la sección IV se presenta el modelo de las tres brechas y se discuten los desafíos que supone la reducción de dichas brechas en distintos escenarios de políticas. En la sección $V$ se exponen las consecuencias socioeconómicas que dejará la crisis y en la VI se plantean, a modo de conclusión, un conjunto de propuestas de políticas macro-, meso- y microeconómicas que viabilizarían un nuevo sendero de desarrollo en la región, con transformación productiva, inclusión social y sostenibilidad medioambiental, para superar así la disfuncionalidad del modelo vigente.

\section{Alcances globales de la pandemia}

\section{Alcances sanitarios}

Tras la rápida propagación a escala global del COVID-19, hoy nuestra civilización enfrenta una crisis sanitaria, social y económica de enorme magnitud (CEPAL, 2020a). Si bien el mundo y la región pudieron enfrentar adecuadamente los brotes de gripe aviar en 2003 y gripe porcina en 2009 (transmitidas 
por los virus H5N1 y H1N1, respectivamente), la emergencia sanitaria del COVID-19 ha implicado esfuerzos de contención mucho mayores, y los niveles de contagios y decesos son los más elevados desde la pandemia de gripe española, que afectó al mundo hace un siglo. En efecto, según datos de la Organización Mundial de la Salud (OMS), actualizados al 25 de febrero de 2021, la mortalidad por COVID-19 asciende a 2.486.679 personas²; en tanto, según estimaciones históricas presentadas en Murillo (2011), la gripe española se cobró entre 20 y 40 millones de vidas. Por otro lado, la gripe de Hong Kong (1968) ocasionó una mortalidad levemente inferior a la que ha generado hasta ahora el COVID-19, según las cifras presentadas en el cuadro 1.

\section{Cuadro 1}

Mortalidad mundial ocasionada por pandemias de gripe en los siglos XX y XXI

(En número de personas)

\begin{tabular}{llcl}
\hline Años & Nombre & Mortalidad & Virus \\
\hline $1918-1919$ & Gripe española & 20000000 a 40000000 & H1N1 \\
\hline $1957-1959$ & Gripe asiática & 2000000 & H2N2 \\
\hline 1968 & Gripe de Hong Kong & 1000000 & H3N2 \\
\hline $2003^{a}$ & Gripe aviar & 455 & H5N1 \\
\hline $209^{b}$ & Gripe porcina & 18449 & H1N1 \\
\hline $2019-$ & Enfermedad por coronavirus & 2486679 & SARS-CoV2 \\
\hline
\end{tabular}

Fuente: G. Murillo, "Recordando la gripe española", Medicina Interna de México, vol. 27, № 5, Ciudad de México, 2011 y Organización Mundial de la Salud (OMS).

a Datos actualizados al 10 de julio de 2020.

b Datos actualizados al 1 de agosto de 2010.

En relación con el impacto mundial del COVID-19, en el cuadro 2 se presenta un conjunto de datos que es importante considerar. Se observa que, de los más de 111 millones de casos a nivel mundial, las regiones con menor incidencia son Oceanía, con algo más de 58.000 casos $(0,1 \%$ del total mundial), África, con 3.697.776 casos (3,3\%), y Oriente Medio, con 5.523.592 casos (4,9\%). Por otro lado, las regiones con mayor incidencia son Europa, con 36.794 .659 casos (32,9\%), América del Norte, con 28.807.637 casos (25,7\%), América Latina y el Caribe, con 21.066.155 casos (18,8\%), y Asia, con 16.051.119 (14,3\%). En términos de decesos, las tendencias son relativamente similares; nuevamente Oceanía, África y Oriente Medio son las regiones que registran menores niveles de defunciones por COVID-19, con proporciones del 0,05\%, el 3,7\% y el $4,5 \%$ del total mundial, respectivamente (columna (1) a (4)).

\section{Cuadro 2}

Regiones del mundo: contagios y decesos a causa del COVID-19, al 25 de febrero de 2021 (En número de personas y porcentajes)

\begin{tabular}{lrrrrrrc}
\hline Región & $\begin{array}{c}\text { Casos } \\
\text { (número) } \\
(1)\end{array}$ & $\begin{array}{c}\text { Muertes } \\
\text { (número) } \\
(2)\end{array}$ & $\begin{array}{c}\text { Casos } \\
\text { (porcentajes } \\
\text { del total) } \\
(3)\end{array}$ & $\begin{array}{c}\text { Muertes } \\
\text { (porcentajes } \\
\text { del total) } \\
(4)\end{array}$ & $\begin{array}{c}\text { Casos } \\
\text { (por millón } \\
\text { de habitantes) } \\
(5)\end{array}$ & $\begin{array}{c}\text { Muertes } \\
\text { (por millón } \\
\text { de habitantes) } \\
(6)\end{array}$ & $\begin{array}{c}\text { Relación entre } \\
\text { muertes y casos } \\
\text { (porcentajes) } \\
(7)=(6) /(5) * 100\end{array}$ \\
\hline África & 3697776 & 91928 & 3,3 & 3,7 & 3056 & 76 & 2,5 \\
\hline América del Norte & 28807637 & 520779 & 25,7 & 20,9 & 78734 & 1423 & 1,8 \\
\hline América Latina y el Caribe & 21066155 & 667308 & 18,8 & 26,8 & 32453 & 1028 & 3,2 \\
\hline Asia & 16051119 & 254807 & 14,3 & 10,2 & 3842 & 61 & 1,6 \\
\hline Europa & 36794659 & 837638 & 32,9 & 33,7 & 43399 & 988 & 2,3 \\
\hline Oriente Medio & 5523592 & 112987 & 4,9 & 4,5 & 15668 & 320 & 2,0 \\
\hline Oceanía & 58271 & 1219 & 0,1 & 0,0 & 1382 & 29 & 2,1 \\
\hline Mundo & 111999954 & 2486679 & 100 & 100 & 14649 & 325 & 2,2 \\
\hline
\end{tabular}

Fuente: Elaboración propia, sobre la base de cifras de la Organización Mundial de la Salud (OMS) [en línea] https://worldhealthorg. shinyapps.io/covid/ y Banco Mundial.

2 Si bien las cifras relativas a la pandemia se actualizan periódicamente en el sitio de la OMS ([en línea] https://worldhealthorg. shinyapps.io/covid/), para efectos de este artículo la fecha límite de análisis es el 25 de febrero de 2021. Alternativamente, se pueden revisar los datos del Coronavirus Resource Center de la John Hopkins University ([en línea] https://coronavirus.jhu.edu/ map.html), que muestran tendencias similares a los datos de la OMS. 
En cuanto a Asia, si bien es una de las regiones con mayores niveles de incidencia, presenta una menor tasa de mortalidad en el contexto de las regiones más afectadas, y los decesos representan un $10,2 \%$ del total mundial, debido en parte a políticas sanitarias adecuadas. Por otro lado, América del Norte registra 520.779 defunciones, lo que representa un 20,9\% del total mundial: los Estados Unidos es el país que alcanza la mayor proporción del subtotal regional tanto en número de contagios como de muertes, en relación con el Canadá. En Europa, en tanto, las muertes por COVID-19 llegan a 837.638, lo que equivale al 32,9\% del total. Esta región fue una de las primeras en las que el virus se propagó a gran escala desde China a comienzos de 2020 y la que sufrió con mayor dramatismo su letalidad. Italia y España fueron de hecho los países que presentaron el mayor número de contagios y muertes en los primeros meses del brote de la enfermedad; a fines de 2020, la Federación de Rusia, Francia y el Reino Unido muestran altos niveles de incidencia. Si bien se ha logrado contener la crisis en los países de ese continente, mediante medidas sanitarias y apoyos fiscales de gran envergadura, lo que ha permitido ir relajando las medidas de confinamiento y restricción de la movilidad humana, muchos países han experimentado rebrotes que han significado volver a las condiciones iniciales de emergencia.

Finalmente, sobresale el hecho de que América Latina y el Caribe no solo es una de las regiones con mayor número de casos positivos, después de Europa y América del Norte, sino también la que ha debido lamentar el segundo mayor número de fallecimientos por COVID-19 a nivel mundial: 667.308 personas, que representan el $26,8 \%$ de la mortalidad mundial ocasionada por esta pandemia. En las columnas (5) y (6) del cuadro 2 se muestra la incidencia de la enfermedad por medio del número de casos y decesos por millón de habitantes en cada región. En términos de casos, se observa que las regiones con mayor número de contagiados por millón de habitantes son América del Norte y Europa, seguidas por América Latina y el Caribe. En términos de decesos el orden se altera: América del Norte se ubica también en primer lugar, con 1.423 fallecidos por millón de habitantes, pero seguida de América Latina y el Caribe (1.028) y luego Europa (988). Sin embargo, más allá de estas diferencias regionales ajustadas, en la columna (7) del cuadro 2, en la que se presenta la relación entre fallecidos y contagiados como porcentaje, se puede observar que América Latina y el Caribe supera a todas las otras regiones del mundo, con un 3,2\%. Esta medición más precisa evidencia la mayor fragilidad de la región en términos sanitarios para contener la propagación del virus, dadas la fragmentación y la insuficiencia de sus sistemas sanitarios, en relación con las regiones más desarrolladas del orbe.

\section{Efectos económicos}

El brote de la enfermedad por coronavirus en la ciudad china de Wuhan, en enero de 2020, no tardó en expandirse al resto del mundo, transformándose en pandemia. Los gobiernos del mundo se vieron forzados a aplicar medidas sanitarias de confinamiento y distanciamiento físico, con el fin de frenar la propagación del virus (CEPAL, 2020a y 2020h). Estas medidas, aún vigentes, prácticamente paralizaron la economía global. El confinamiento temprano que adoptó China significó un choque para varios países que dependen de los vínculos comerciales con ese país, incluidos aquellos cuyo patrón de especialización descansa marcadamente en exportaciones primarias, dada la caída de los volúmenes demandados y de los precios de estos productos, si bien se espera que hacia fines de año algunos de ellos se recuperen. Junto con lo anterior, como resultado de la dominancia de China en las cadenas de valor mundiales, la producción ha experimentado cambios que se han difundido velozmente, afectando al conjunto de países que participan en ellas (CEPAL, 2020a).

Así, la crisis sanitaria devino en una crisis económica de enorme magnitud, comparable con las graves crisis cíclicas por las que atravesó el capitalismo en el siglo XX. En el Estudio Económico de América Latina y el Caribe, 2020, publicado por la CEPAL, se afirma que "la pandemia de COVID-19 llevó a la economía global a la peor recesión desde la Segunda Guerra Mundial” (CEPAL, 2020h, pág. 27). Por otro lado, en CEPAL (2020j) se proyecta para 2020 una caída del PIB mundial del orden del 4,4\%. Este 
hecho se ilustra en el gráfico 1, en el que se presenta el crecimiento del PIB desagregado por grandes regiones y algunos países de alta incidencia en la economía mundial. De acuerdo con las proyecciones, el PIB de las economías desarrolladas, cuyo ritmo de crecimiento ya se venía desacelerando desde 2018, caería un 5,8\% en 2020. En esta agrupación, las economías de la zona del euro experimentarían la mayor caída, de un 8,0\%. La economía del Reino Unido se contraería un 10,0\%, en tanto que los Estados Unidos y el Japón verían reducido su producto con caídas del 4,1\% y el 5,6\%, respectivamente.

\section{Gráfico 1}

Regiones y países seleccionados: tasa de crecimiento del PIB, 2018 y 2019, y proyecciones para 2020 y 2021

(En porcentajes)

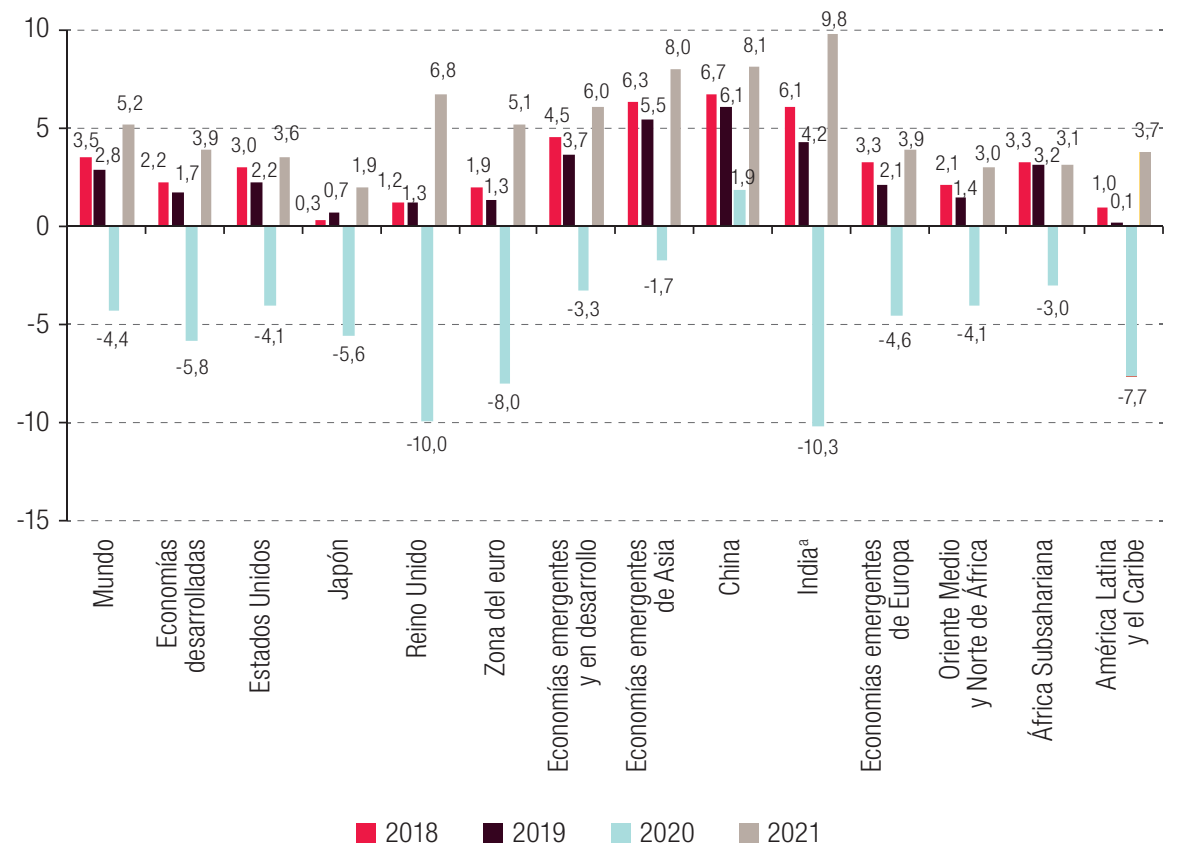

Fuente: Elaboración propia, sobre la base de cifras de la Comisión Económica para América Latina y el Caribe (CEPAL); Banco Mundial, Global Economic Monitor (GEM) [base de datos en línea] https://datacatalog.worldbank.org/dataset/globaleconomic-monitor [fecha de consulta: junio de 2020]; Organización de Cooperación y Desarrollo Económicos (OCDE), OECD Economic Outlook, París, OECD Publishing, junio de 2020; Banco Central Europeo (BCE), "Eurosystem staff macroeconomic projections", junio de 2020 [en línea] https://www.ecb.europa.eu/pub/projections/html/index.en.html; y Naciones Unidas, World Economic Situation and Prospects as of mid-2020, Nueva York, 2020.

a Las cifras de la India corresponden al año fiscal, que comienza en abril y termina en marzo del año siguiente.

Las economías emergentes y en desarrollo presentarían, por su parte, un menor decrecimiento, cercano al 3,3\%, pero este desempeño sería considerablemente inferior a la dinámica de crecimiento que registraron en 2018 y 2019. Dentro de este grupo, las economías de Asia Oriental y el Pacífico crecerían un 1,7\%. China continuaría creciendo, pero al 1,9\%, después de haber sostenido el crecimiento mundial con ritmos del 6,7\% y el 6,1\% en 2018 y 2019, respectivamente. La India, en tanto, experimentaría una contracción del 10,3\% en su ritmo de crecimiento. Las economías de Oriente Medio y el Norte de África experimentarían una caída significativa de su PIB, del 4,1\%.

En el conjunto de economías en desarrollo, sobresale el caso de América Latina y el Caribe. Conforme la región ha sido la más afectada en el mundo en términos sanitarios, como se mostró en el cuadro 2, en el gráfico 1 puede observarse que también sería la región más afectada en términos económicos, con una contracción de su PIB del orden del 7,7\%. Esta fuerte caída de la producción regional, como se explicará en lo que sigue, radica, por un lado, en el colapso del comercio mundial y la caída de los precios internacionales de los productos que la región exporta y, por otro lado, en 
la depresión que ha sufrido la demanda interna de las economías de la región, que se ha traducido a su vez en marcados aumentos de los niveles de desocupación y el cierre de unidades productivas, como consecuencia de las medidas generalizadas de confinamiento que han tomado las autoridades sanitarias. Como se verá, estos resultados incidirán también fuertemente en el área social, en términos de pobreza, pobreza extrema y desigualdad.

Por último, de acuerdo con proyecciones recientes presentadas en CEPAL (2020j), se espera que tanto el mundo en su conjunto como todas las regiones y países analizados experimenten recuperaciones de su tasa de crecimiento. Evidentemente, el logro de estos resultados dependerá en primer lugar de que aumente la eficacia en la contención de la pandemia, y en especial de que se logre avanzar en las estrategias nacionales de inmunización, dados los esfuerzos que han venido realizando los laboratorios internacionales para proveer diferentes vacunas contra el COVID-19. El éxito de estas estrategias podría reducir los niveles de incertidumbre global y con ello se podría reestimular al sector real de la economía, acelerando así el crecimiento económico, la reactivación del comercio y la recuperación del empleo y la formación de capital.

El comercio mundial ha experimentado un notorio colapso como consecuencia de la pandemia. La Organización Mundial del Comercio (OMC) proyecta para 2020 una caída de los flujos comerciales de mercancías en un rango que varía entre el $13 \%$ y el $32 \%$ a escala mundial (con datos disponibles hasta mayo), como puede observarse en el gráfico 2. Según la CEPAL (2020h), a diferencia de crisis anteriores, el comercio de servicios ha resultado más afectado que el de bienes durante la pandemia. En particular, los servicios de transporte relacionados con el comercio de bienes se han visto severamente afectados por la contracción que han sufrido estos flujos. Por otro lado, las medidas sanitarias adoptadas en el mundo han incluido la restricción de la movilidad internacional de las personas, lo que ha tenido una fuerte incidencia en el sector del turismo. Sobre la base de datos de la Organización Mundial del Turismo (OMT), la CEPAL (2020h) señala que entre enero y mayo de 2020 la actividad del sector cayó un 56\% y la proyección para el año es de una contracción que podría variar entre un 60\% y un 80\%.

\section{Gráfico 2}

Tasa de variación interanual del volumen del comercio mundial de bienes, enero de 2003 a mayo de 2020

(En porcentajes, sobre la base de un índice desestacionalizado)

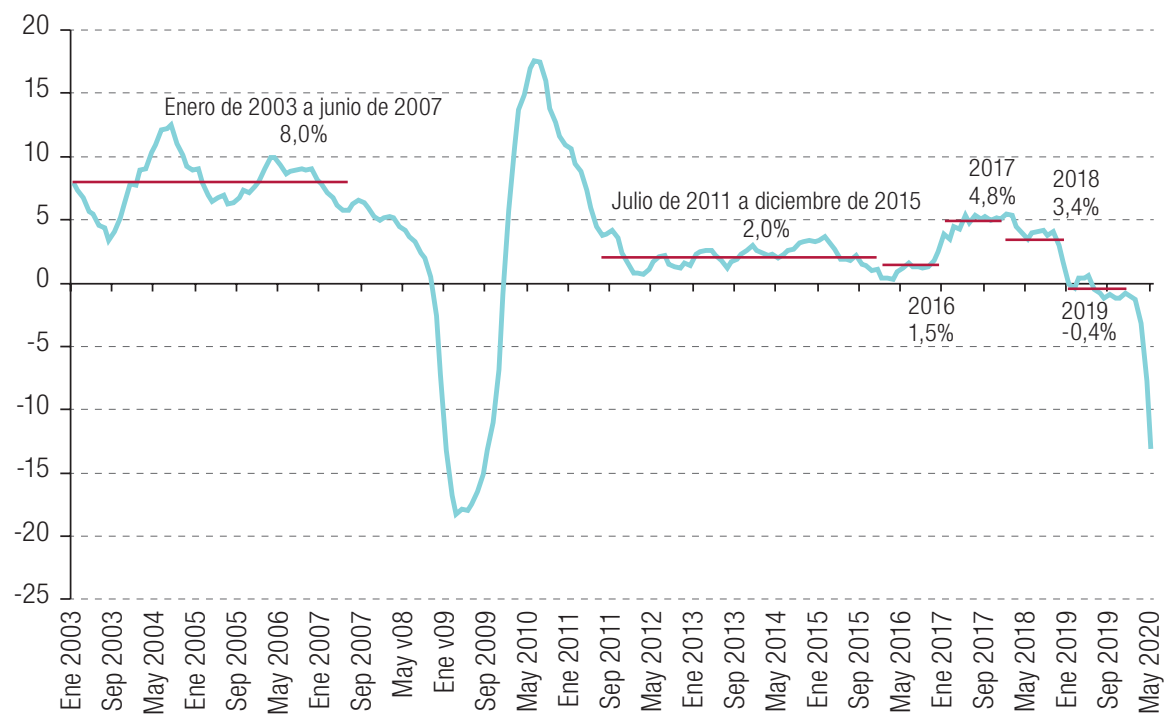

Fuente: Comisión Económica para América Latina y el Caribe (CEPAL), sobre la base de Netherlands Bureau of Economic Policy Analysis (CPB), World Trade Monitor [base de datos en línea] https://www.cpb.nl/en/worldtrademonitor; y Organización Mundial del Comercio (OMC), "Trade forecast press conference", 8 de abril de 2020 [en línea] https://www.wto.org/ english/news_e/spra_e/spra303_e.htm. 
Dada la contracción mundial de la demanda de exportaciones, de acuerdo con las primeras proyecciones para 2020 se había estimado que los precios de los productos básicos experimentarían marcadas caídas respecto de los registrados en 2019. Ello tendría un efecto negativo en los términos de intercambio de los países exportadores de estos productos. Así, se esperaba que el precio del petróleo cayera un $36 \%$. En tanto, se estimaba que los precios de los productos agropecuarios resultarían menos golpeados por la crisis, con una disminución esperada de casi un $2 \%$. En cuanto a los metales y minerales, se proyectaba una caída de su precio de solo un 0,1\%, pero con fuertes diferencias en términos de su composición interna. En efecto, los precios de los metales industriales, incluido el cobre, caerían un 5\%. Esta caída se compensaría con el alza del precio de metales preciosos como el oro, que mostraban un incremento (al menos hasta el 24 de julio de 2020) de un 28\% (véase el cuadro 3).

Cuadro 3

Variación interanual de los precios promedio anuales de productos básicos, 2016-2020 (En porcentajes)

\begin{tabular}{|c|c|c|c|c|c|}
\hline & 2016 & 2017 & 2018 & 2019 & $2020^{\mathrm{a}}$ \\
\hline Productos agropecuarios & 4,9 & 0,5 & 0,5 & $-3,0$ & $-1,7$ \\
\hline Alimentos, bebidas tropicales y oleaginosas & 6,8 & $-0,6$ & $-2,8$ & $-3,7$ & $-1,5$ \\
\hline Alimentos & 11,5 & $-0,2$ & $-4,3$ & $-0,6$ & $-2,5$ \\
\hline Bebidas tropicales & 0,6 & $-1,7$ & $-10,1$ & $-5,0$ & 6,5 \\
\hline Aceites y semillas oleaginosas & 2,4 & $-1,0$ & 1,4 & $-7,7$ & $-2,0$ \\
\hline Materias primas silvoagropecuarias & $-2,3$ & 4,9 & 13,4 & $-0,7$ & $-2,4$ \\
\hline Minerales y metales & $-0,8$ & 23,3 & 4,2 & $-1,0$ & $-0,1$ \\
\hline Energíab $^{b}$ & $-16,3$ & 23,5 & 25,6 & $-9,1$ & $-29,6$ \\
\hline Petróleo crudo & $-15,7$ & 14,5 & 29,4 & $-10,2$ & $-35,6$ \\
\hline Total productos primarios & $-4,0$ & 14,5 & 9,8 & $-4,6$ & $-10,9$ \\
\hline Total productos primarios (excluida la energía) & 2,3 & 10,8 & 2,3 & $-2,0$ & $-0,9$ \\
\hline
\end{tabular}

Fuente: Comisión Económica para América Latina y el Caribe (CEPAL), sobre la base de Banco Mundial, "World Bank Commodities Price Data (The Pink Sheet)", 2 de junio de 2020 [en línea] http://pubdocs.worldbank.org/en/774651591120179792/ CMOPink-Sheet-June-2020.pdf; Administración de Información Energética de los Estados Unidos, Short Term Energy Outlook, 7 de julio de 2020, y datos de Bloomberg y Capital Economics.

a Las cifras de 2020 corresponden a proyecciones.

b Esta categoría incluye el petróleo, el gas natural y el carbón.

En materia de políticas macroeconómicas, los gobiernos han adoptado distintas medidas extraordinarias, incluidas reducciones de las tasas de interés por parte de la banca central tanto en economías desarrolladas como emergentes. En lo que respecta a la política fiscal, ambos tipos de economías han desplegado una serie de estímulos fiscales de diversa magnitud en atención a sus tamaños relativos. Estas medidas fiscales se han orientado a paliar los efectos adversos de la crisis en el empleo y en los ingresos de los hogares y se han materializado, por ejemplo, en transferencias a hogares y empresas, períodos de gracia para el pago de impuestos y otras contribuciones, subsidios para el pago de salarios, reducción de impuestos y programas de garantías con fondos públicos para créditos y préstamos.

En cuanto al sector financiero, a pesar de que no se aprecia un deterioro de sus condiciones, persiste una elevada incertidumbre relacionada con los efectos sanitarios y socioeconómicos de la pandemia. Dicha incertidumbre se plasma en la volatilidad que ha caracterizado a los mercados financieros, que se ilustra en el gráfico 3. Medida por el índice VIX, la volatilidad de estos mercados se elevó hasta alcanzar niveles máximos en su historia a mediados de marzo de 2020, en tanto que se produjeron salidas masivas de capitales desde los mercados emergentes y aumentaron los niveles de riesgo soberano, en particular los de mercados emergentes. Por otro lado, la mayoría de las monedas se han depreciado de manera significativa respecto del dólar estadounidense, dada la naturaleza globalmente contracíclica de esta moneda, cuya tendencia es de fortalecimiento en tiempos recesivos y de debilitamiento ante expectativas de auge y reactivación (véase el gráfico 4). 


\section{Gráfico 3}

Volatilidad en los mercados financieros medida por el índice VIX, 1 de enero de 2007 a 24 de julio de 2020

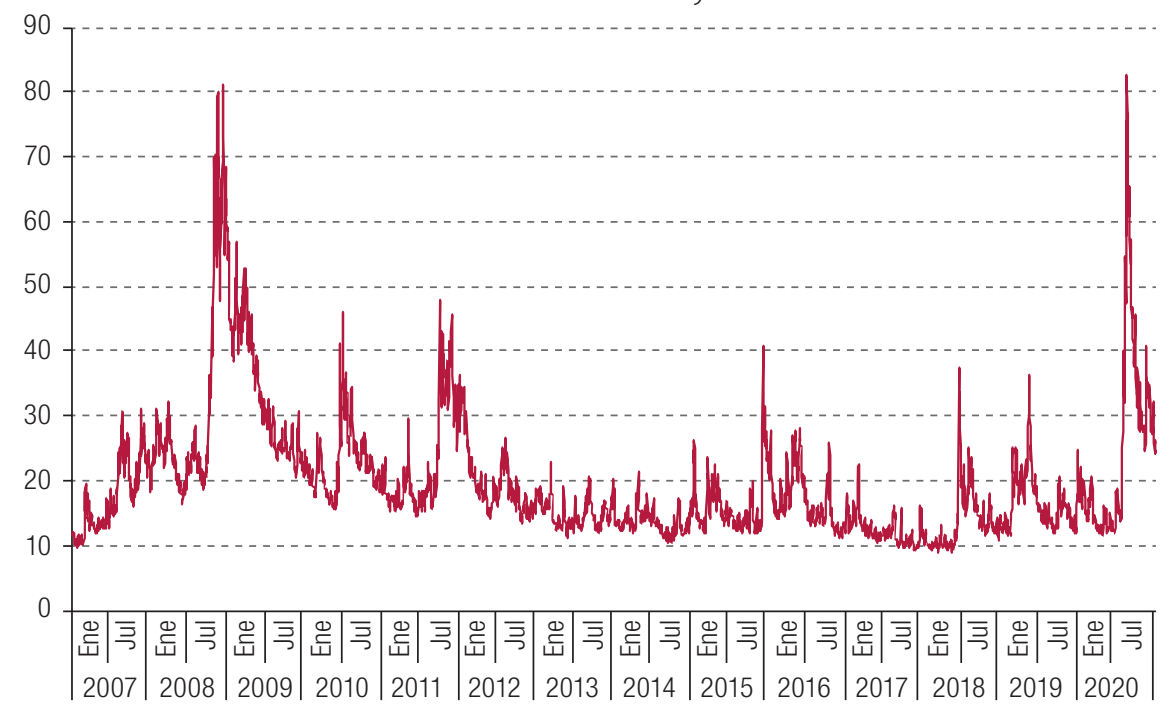

Fuente: Comisión Económica para América Latina y el Caribe (CEPAL), sobre la base de Bloomberg.

\section{Gráfico 4}

Índice del tipo de cambio del dólar respecto de las principales monedas, 1 de enero de 2019 a 16 de julio de 2020 (Índice DXY, base enero de 2013=100)

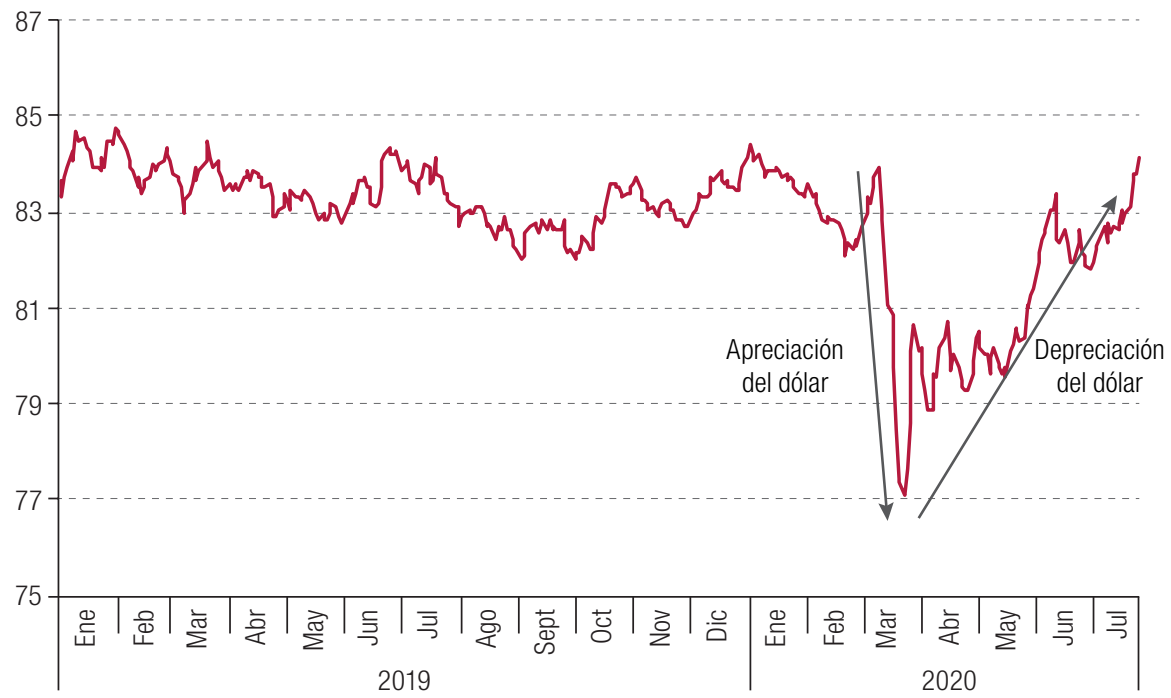

Fuente: Comisión Económica para América Latina y el Caribe (CEPAL), sobre la base de Bloomberg.

Nota: El índice DXY (índice dólar spot) de Bloomberg sigue la evolución del tipo de cambio del dólar estadounidense respecto de una canasta de diez monedas de relevancia mundial. 


\section{América Latina y el Caribe antes de la crisis sanitaria}

En la sección II se ha mostrado que la región ha sido la más golpeada en el mundo en términos sanitarios y económicos por la pandemia. En esta sección se argumenta que ese hecho es también consecuencia de los rasgos recesivos que caracterizaron el sexenio 2014-2019, en el que la región creció a un exiguo 0,4\% promedio anual. Ese período estuvo caracterizado, en primer lugar, por la persistencia de los choques recesivos que experimentó la economía mundial como efecto de la crisis financiera mundial de 2008 y 2009 (la crisis del Atlántico Norte, como la denomina Ocampo (2020)) y de la crisis de la zona del euro de 2011, la elevada volatilidad financiera mundial, el fin del ciclo de auge de los productos básicos y sucesos geopolíticos y económicos recientes, como las tensiones comerciales entre China y los Estados Unidos.

Este contexto externo ha agudizado los persistentes factores estructurales internos que caracterizan a las economías regionales, entre ellos la heterogeneidad estructural o brecha productiva interna, el crecimiento restringido por la balanza de pagos, la contracción de la demanda efectiva, especialmente en materia de inversión productiva, la reprimarización de las canastas de exportaciones, la baja complejidad de la matriz sectorial de la producción en términos de conocimiento, innovación e investigación y desarrollo $(1+D)$, el limitado espacio fiscal para las políticas sociales y productivas, y el deterioro de las condiciones en el ámbito del empleo, con recrudecimiento de la informalidad y la secular regresión de la distribución factorial del ingreso en desmedro de la masa salarial. Todo ello, antes de la crisis, ya venía produciendo retrocesos sociales en materia de pobreza, pobreza extrema y distribución personal (y de hogares) del ingreso (véase CEPAL, 2020a, 2020b y 2020i, y Abeles, Pérez Caldentey y Porcile, 2020, en esta edición especial). A continuación, se presentan algunos hechos estilizados que ilustran los rasgos estructurales internos y externos de la dinámica económica regional anterior a la crisis ocasionada por la pandemia.

\section{Crecimiento inestable y volátil}

En una perspectiva de largo plazo, América Latina y el Caribe se ha caracterizado por tasas de crecimiento del producto menores que las que alcanzan las economías desarrolladas y otras regiones periféricas y emergentes. Un rasgo aún más característico de su rezago en materia de desarrollo relativo es su dificultad para sostener tasas de crecimiento en períodos de auge y la relativa persistencia de bajas tasas en períodos de recesión y de reactivación. Este rasgo puede ser caracterizado mediante la volatilidad real en América Latina. En el gráfico 5 se presenta la dinámica del crecimiento latinoamericano de 1950 a 2019. Dos hechos muy claros surgen de una primera observación del gráfico: i) las mayores tasas alcanzadas por la región corresponden a los años comprendidos entre 1950 y 1980, un período histórico caracterizado por políticas desarrollistas y un proceso de industrialización guiado por el Estado, y ii) después de la crisis latinoamericana de la deuda externa, de la cual comenzó a recuperarse a partir de 1983, la región retomó ritmos de crecimiento positivos (con las excepciones de 1990, 2009, 2016 y, según lo indicado en la sección anterior, 2020).

El período 1983-2020 representa un retorno a una dinámica productiva basada en ventajas comparativas estáticas, en un contexto de hiperglobalización de la economía mundial. En este período el crecimiento se produce a tasas menores que las registradas en el período anterior. Al ajustar esta tendencia mediante el filtro Hodrick-Prescott, se aprecia con claridad la persistente variabilidad real de las economías de la región y la caída de la tasa de crecimiento tendencial a partir de la década de 1980. 


\section{Gráfico 5}

América Latina: tasa de crecimiento del PIB real, 1950-2019

(En porcentajes)

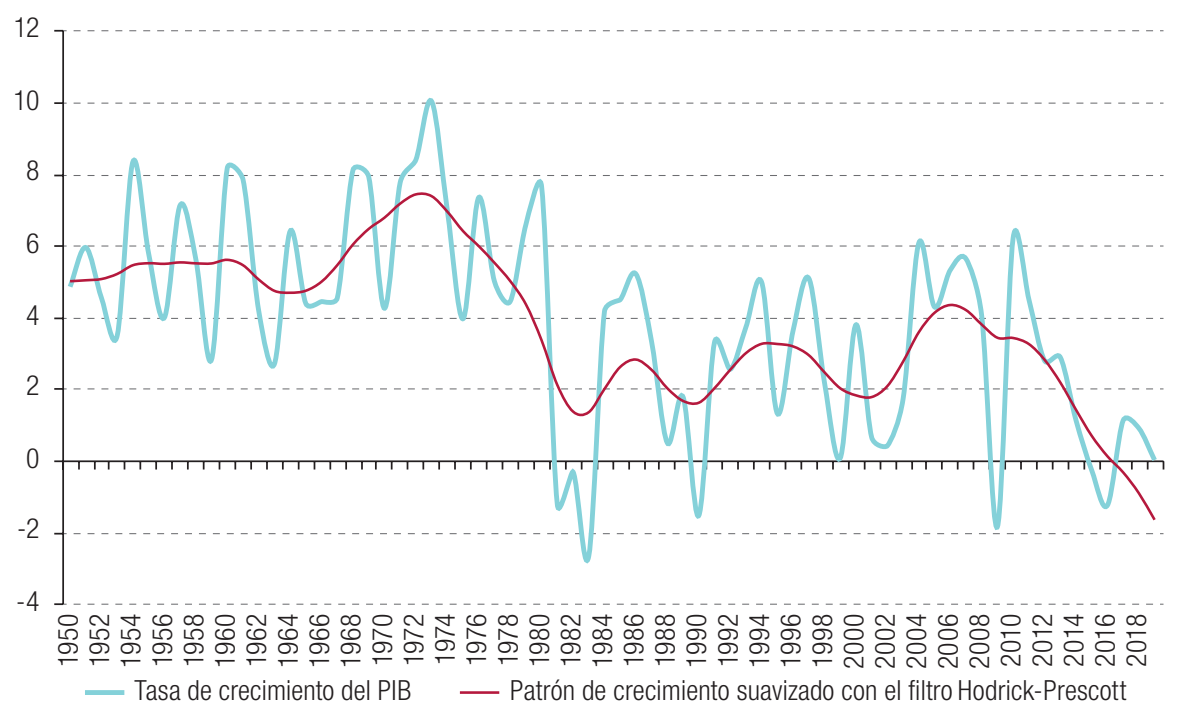

Fuente: Elaboración propia, sobre la base de cifras de la Comisión Económica para América Latina y el Caribe (CEPAL).

Una medida más directa de la volatilidad del crecimiento regional se presenta en el gráfico 6. Allí se relacionan las tasas de crecimiento promedio efectivas del PIB de diferentes períodos (eje horizontal) con sus correspondientes desviaciones estándar (eje vertical). Se aprecia que en el período que va de 1950 a 1979 el crecimiento fue más alto y la volatilidad menor, en tanto que lo opuesto sucedió en el período comprendido entre 1980 y 2020. Una menor vulnerabilidad externa y una mayor acumulación de capacidades productivas internas, asociadas a las políticas productivas en los años del desarrollismo, pueden explicar este quiebre histórico del patrón de crecimiento regional.

Gráfico 6

América Latina: volatilidad del crecimiento, 1950-2019

(En porcentajes y desviaciones estándar)

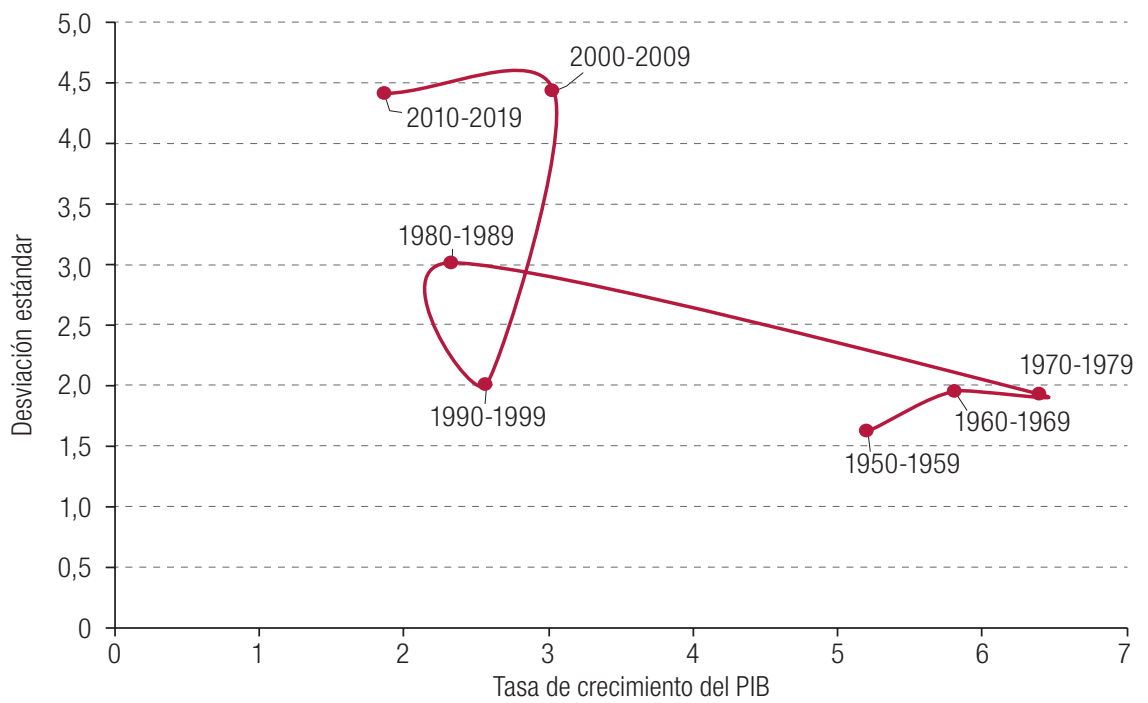

Fuente: Elaboración propia, sobre la base de cifras de la Comisión Económica para América Latina y el Caribe (CEPAL). 


\section{Crecimiento con restricción externa}

El crecimiento con restricción externa constituye uno de los hechos estilizados más característicos del disfuncional patrón de desarrollo regional. La idea central de este concepto se relaciona con la incapacidad de las economías periféricas de crecer a una tasa concordante con la absorción total de la fuerza de trabajo, incluidos los altos niveles de subempleo de baja productividad que caracterizan la dinámica de desarrollo en la periferia (la heterogeneidad estructural), debido a su bajo potencial de generación de divisas. Raúl Prebisch abordó esta problemática, planteando que ella radicaba en el hecho de que la elasticidad ingreso de los bienes primarios exportados por la periferia es menor que la elasticidad ingreso de las importaciones de manufacturas producidas por las economías centrales (Prebisch, 1962). Ello supone a largo plazo una divergencia entre ambos tipos de economías en materia de crecimiento, dadas las asimetrías productivas y tecnológicas que se observan entre ellas y las presiones al endeudamiento externo que debe enfrentar la periferia debido a la escasez estructural de divisas. Prebisch (1963) amplió estas ideas bajo el concepto de estrangulamiento externo, que "consiste en una sucesión de desequilibrios de la balanza de pagos de tal magnitud que la escasez de divisas primero dificulta y luego bloquea la continuidad de la sustitución de importaciones" (Rodríguez, 2006, pág. 143).

Aproximaciones similares al enfoque del estrangulamiento externo plantean Seers (1962) y Rodríguez (1977), pero es Thirlwall (1979) quien formaliza el concepto de tasa de crecimiento compatible con el equilibrio externo. En una economía mundial de dos regiones, centro y periferia, dicha tasa se expresa en la siguiente ecuación: $y^{E}=\frac{\varepsilon}{\pi} y^{c}$, donde $y^{E}$ e $y^{C}$ representan, respectivamente, las tasas de crecimiento de la periferia y el centro, $\varepsilon$ la elasticidad ingreso de la demanda mundial de exportaciones provenientes de la periferia y $\pi$ la elasticidad ingreso de las importaciones provenientes del centro. Estas elasticidades, a su vez, dependen de las capacidades tecnológicas de la periferia en comparación con las del centro, porque son estas las que definen la participación del país en los mercados en que crecen más rápidamente las demandas interna y externa. El crecimiento de la periferia será menor que el del centro y habrá divergencia entre las dos regiones cada vez que el cociente $\frac{\varepsilon}{\pi}$ sea menor que 1. Esta divergencia se mantendrá mientras las economías periféricas no sean capaces de modificar dicho cociente mediante políticas industriales, productivas y tecnológicas que permitan aumentarlo para reducir el estrangulamiento externo.

La relación entre crecimiento y sector externo se ilustra en el gráfico 7, en el que se presentan el saldo de la balanza comercial como porcentaje del PIB (en el eje horizontal) y la tasa de crecimiento del PIB (en el eje vertical). Períodos de alto crecimiento con déficit de la balanza comercial son seguidos por períodos de bajo crecimiento en que las economías de la región son obligadas a crecer e invertir menos para generar superávits y pagar la deuda. Solo en los años de rápida industrialización anteriores a la década de 1970 y en los años del auge de las materias primas se logró crecimiento con superávit de la balanza comercial (aunque en este último caso el crecimiento fue más bajo). La situación que emerge a inicios de la década de 2020, a partir de la crisis ocasionada por la pandemia, es en extremo compleja. 


\section{Gráfico 7}

América Latina: saldo de la balanza comercial como proporción del PIB y tasa de crecimiento del PIB, 1950-2019

(En porcentajes)

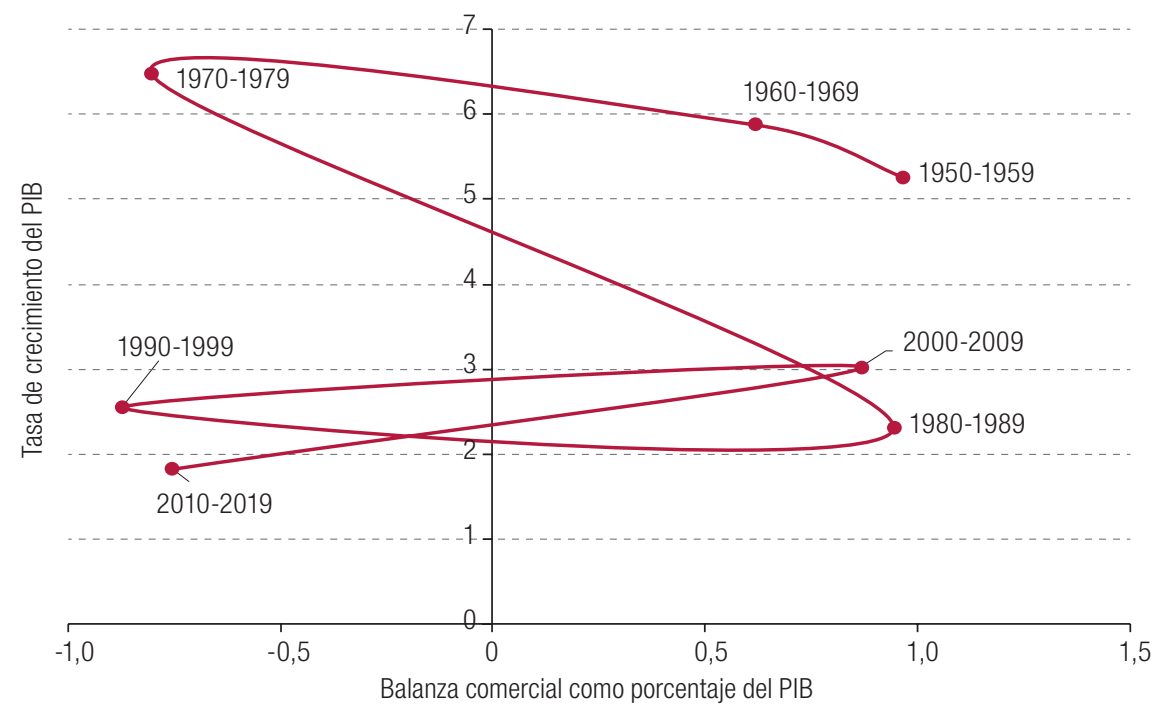

Fuente: Elaboración propia, sobre la base de cifras de la Comisión Económica para América Latina y el Caribe (CEPAL).

\section{Baja productividad laboral como factor subyacente de la competitividad "espuria"}

A mediados de los años ochenta Fernando Fajnzylber elaboró dos conceptos opuestos para caracterizar los patrones de competitividad y desarrollo en la región. Al patrón competitivo basado en precios, tipos de cambio sobrevaluados, depresión salarial y ventajas comparativas estáticas basadas en la extracción de recursos naturales lo denominó competitividad "espuria" y lo diferenció de un patrón competitivo basado en la incorporación del progreso técnico en el proceso productivo y el incremento de la productividad laboral mediante la capacitación de la fuerza de trabajo, al que caracterizó como competitividad "auténtica" (Fajnzylber, 1990).

En el gráfico 8 se presenta una descomposición del crecimiento del PIB para el conjunto de países de América Latina y el Caribe y otros países y regiones durante el período 2000-2019. Esta descomposición se realiza midiendo las contribuciones del empleo y la productividad laboral a las tasas de crecimiento del $\mathrm{PIB}^{3}$. Se observa que en la región el crecimiento promedio alcanzado en las dos últimas décadas fue generado en un 76\% mediante la acumulación de empleo y en un 24\% mediante incrementos de la productividad laboral. Esta situación contrasta notoriamente con el patrón observado en las economías asiáticas: en China la contribución de la productividad es de un 96\% y la del trabajo de un 4\%; en la India la relación es de casi un $80 \%$ y un 20\%, respectivamente, mientras que en el Japón es del orden del $70 \%$ y el $30 \%$, y en la República de Corea del $66 \%$ y el $34 \%$. En Europa y los Estados Unidos las diferencias son más ajustadas; no obstante, en ambos casos las contribuciones de la productividad laboral son mayores que la de la región (de un $46 \%$ y un 64\%, respectivamente).

${ }^{3}$ El ejercicio se realiza de acuerdo con el siguiente procedimiento. Si $Y$ representa el nivel del PIB y $E$ el nivel de empleo, la productividad laboral media se define entonces por el cociente $P_{E} \equiv \frac{Y}{E}$. De acuerdo con estas definiciones es trivial expresar el PIB mediante la expresión $Y=P_{E} \cdot E$. Al aplicar una transformación logarítmica a esta ecuación y luego el diferencial total con respecto al tiempo, se tendrá que $\hat{Y}=\widehat{P_{E}}+\hat{E}$, donde $\hat{Y}$ representa la tasa de crecimiento del PIB, $\widehat{P_{E}}$ el crecimiento de la productividad laboral media y $\hat{E}$ el crecimiento del empleo. Normalizando la ecuación por la tasa de crecimiento del PIB, se obtiene que la contribución de la productividad laboral media es el cociente $\frac{P_{E}}{\hat{Y}}$ y la del empleo el cociente $\frac{\hat{E}}{\hat{Y}}$. 


\section{Gráfico 8}

América Latina y el Caribe y otras regiones y países: contribución del empleo y la productividad laboral al crecimiento del PIB, promedio 2000-2019

(En porcentajes)

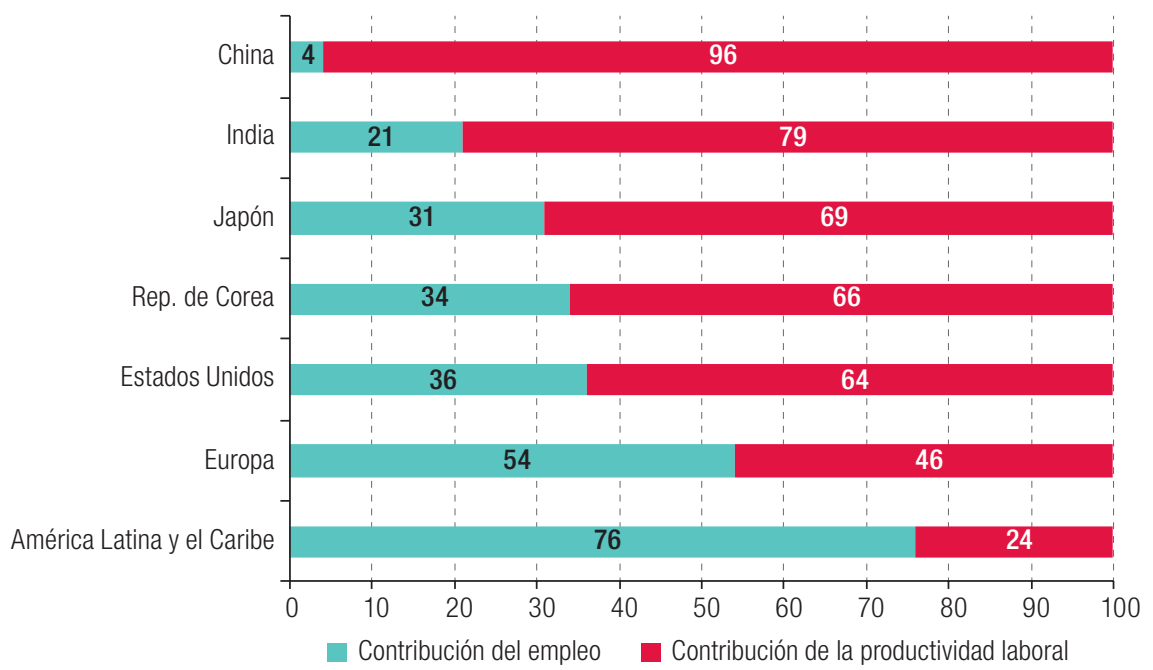

Fuente: Comisión Económica para América Latina y el Caribe (CEPAL), Construir un nuevo futuro: una recuperación transformadora con igualdad y sostenibilidad (LC/SES.38/3-P/Rev.1), Santiago, 2020.

Estos resultados se explican por la distinta intensidad del esfuerzo tecnológico en cada una de estas economías, como se refleja en particular en la evolución de la relación l+D/PIB. La reprimarización que afectó recientemente a América Latina y el Caribe durante el ciclo de auge de los precios de los productos básicos, sumada a la debilidad de las institucionalidades de política industrial existentes en la región, han jugado definitivamente en contra del desarrollo de un proceso de cambio estructural que permita aumentar la contribución de la productividad laboral al crecimiento económico, mediante la mejora de las condiciones de competitividad "auténtica" en las economías de la región.

\section{Patrones de aprendizaje en un contexto de senderos regresivos e histéresis}

Blanchard y Summers (1986) analizaron teórica y empíricamente las persistentes y elevadas tasas de desempleo que registraron las economías de Europa Occidental a partir de la década de 1980. Caracterizaron este hecho como un proceso de histéresis laboral, en el sentido de que un incremento de la tasa de desempleo a corto plazo provocado por un choque recesivo puede presentar una marcada persistencia a mediano plazo e incluso transformarse en desempleo estructural. De acuerdo con Setterfield (2009), la histéresis es un caso especial de dependencia histórica (o path dependency) en el que los efectos de un choque pasado sobre una variable $\mu$, supóngase, por ejemplo, la tasa de desempleo de una economía, pueden afectar el valor actual de la misma, vale decir que $\mu_{t}=f\left(\mu_{t-1}\right)$ y $f^{\prime}\left(\mu_{t-1}\right)>0$, esto es, que la tasa actual de desempleo depende de sus valores anteriores y que un incremento de estos genera un aumento de su valor presente ${ }^{4}$.

Un factor central del análisis consiste en dilucidar si un choque pasado en el desempleo (por ejemplo, como consecuencia de una crisis económica global) sigue un proceso de camino aleatorio (la dinámica exhibe raíz unitaria), lo que equivale a sostener que el choque de desempleo es

\footnotetext{
4 La histéresis es una situación en que los parámetros de la economía cambian a consecuencia de un choque, de tal modo que esta no puede retornar a su situación original cuando el choque cesa. Por eso períodos de elevada apreciación cambiaria o elevado desempleo pueden generar efectos permanentes y no solo fluctuaciones de corto plazo.
} 
permanente o extremadamente persistente, o bien es estacionario con deriva. Al respecto las evidencias econométricas en el mundo y en la región son diversas; no obstante, en el período reciente que sigue a la crisis del Atlántico Norte (2008-2011), tanto algunas economías desarrolladas como América Latina muestran una dinámica de desocupación que sugiere la presencia de histéresis.

En el gráfico 9 se compara la dinámica de creación de valor agregado y productividad laboral en los casos de China, los Estados Unidos y América Latina. Las curvas correspondientes a las economías china y estadounidense indican que conforme los incrementos del valor agregado van acompañados de incrementos de la productividad laboral el nivel de empleo también aumenta. Sobre todo en el caso de China, aumentos sostenidos de la productividad y del empleo confluyeron para elevar rápidamente el PIB. En el caso latinoamericano, esta relación fue mucho más débil. Después de 2009, aumentó el producto con caída de la productividad (lo que sugiere que el producto aumentó por un aumento del empleo de productividad más baja), y a partir de 2014 tanto la productividad como el empleo cayeron, y con ellos el PIB.

\section{Gráfico 9}

América Latina, Estados Unidos y China: productividad laboral y valor agregado (En dólares y miles de millones de dólares)

A. América Latina, 1990-2019

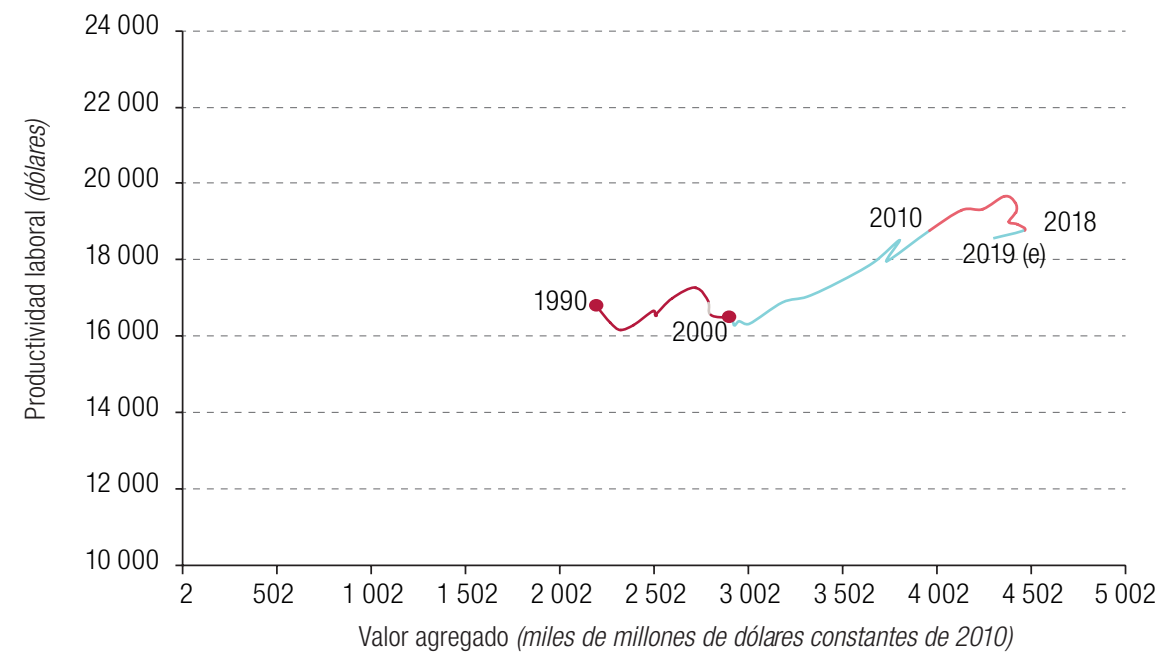

B. Estados Unidos, 1990-2018

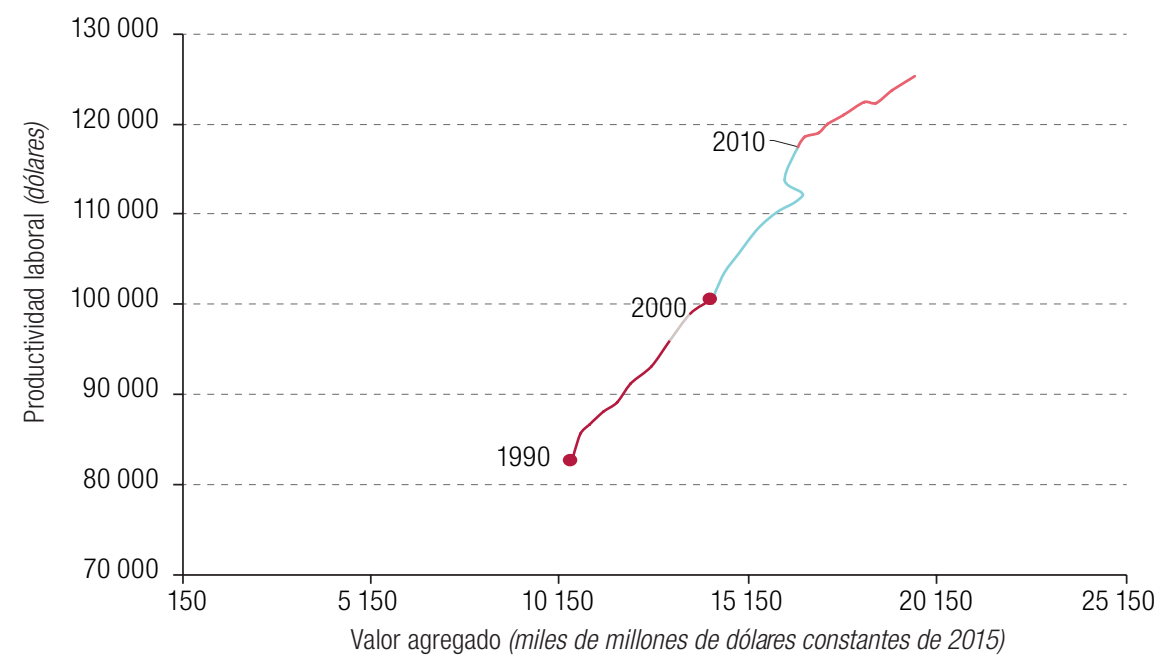




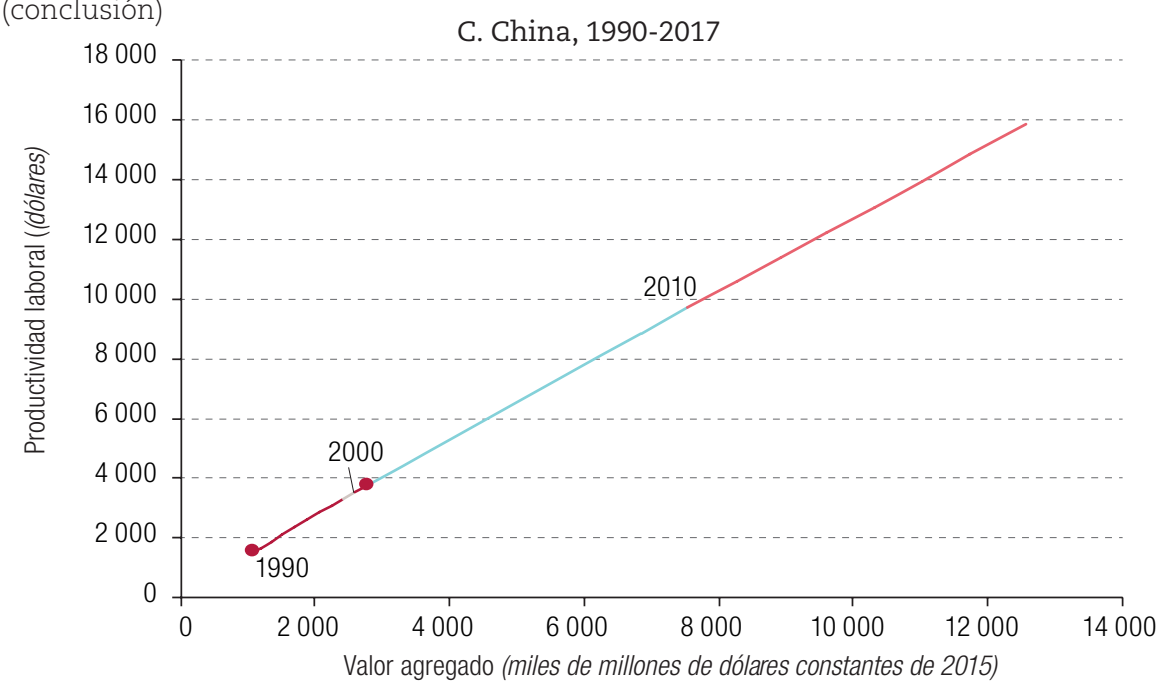

Fuente: Elaboración propia, sobre la base de estadísticas de la Comisión Económica para América Latina y el Caribe (CEPAL); Sistema de Cuentas Nacionales de las Naciones Unidas; CEPAL/Organización Internacional del Trabajo (OIT), "El trabajo en tiempos de pandemia: desafíos frente a la enfermedad por coronavirus (COVID-19)", Coyuntura Laboral en América Latina y el Caribe, № 22 (LC/TS.2020/46), Santiago, mayo de 2020, y "Enfrentar los efectos cada vez mayores del COVID-19 para una reactivación con igualdad: nuevas proyecciones", Informe Especial COVID-19, № 5, Santiago, julio de 2020.

\section{Deterioro secular de la distribución factorial del ingreso}

Un hecho estilizado del capitalismo global durante los últimos siete decenios ha sido el deterioro de la distribución factorial del ingreso en desmedro del trabajo (Torres, 2019). Este fenómeno ha incidido transversalmente tanto en los países desarrollados como en el conjunto de economías en desarrollo. Desde la década de 1950 - en pleno auge del desarrollismo - hasta el período de reciente hiperglobalización se ha venido registrando una permanente caída de la participación de la masa salarial en el PIB, tanto en economías de América Latina como de la Organización de Cooperación y Desarrollo Económicos (OCDE). En América Latina, dicha participación de los salarios ha pasado del $41 \%$ en 1950 al 35\% en 2014, en tanto que en la OCDE ha pasado del 65\% a menos del 59\% en el mismo período (véase el gráfico 10). Hacia 2014, año más reciente con información disponible, la secular caída de la masa salarial presenta fuertes contrastes tanto en las economías de la OCDE como en las latinoamericanas ${ }^{5}$.

En ese sentido, destacan los casos de Bélgica, el Canadá, Dinamarca, Finlandia y Francia, entre otros, donde las participaciones salariales son superiores al 60\%, y las economías de Italia, el Japón y el Reino Unido, que presentan las participaciones más bajas, que fluctúan entre el $43 \%$ y el 48\%. En América Latina, Costa Rica es el país que presenta la mayor participación, de un $50 \%$, seguido del Brasil y Honduras, con participaciones del orden del $45 \%$, en contraste con México, el Perú y Venezuela (República Boliviana de), cuyas participaciones salariales se sitúan entre el 20\% y el 29\%. Los valores de este indicador en América Latina reflejan en alguna medida los problemas estructurales de los mercados laborales de la región, como la flexibilidad laboral, las brechas productivas internas, la especialización productiva y la debilitada capacidad de organización sindical de los trabajadores, hechos que por cierto no incluyen los altos niveles de informalidad. La asimétrica distribución factorial del ingreso es un factor fundamental en términos de la regresividad de la distribución personal; el período reciente de estancamiento en el sexenio 2014-2019 y los profundos retrocesos que generará la crisis sanitaria en el empleo y los salarios hacen pensar razonablemente que ambos tipos de distribuciones empeorarán aún más.

5 Véase el caso de 15 países de América Latina en Alarco (2014) y el caso de la Organización de Cooperación y Desarrollo Económicos (OCDE) en Penn World Table [base de datos en línea] https://www.rug.nl/ggdc/productivity/pwt/. 


\section{Gráfico 10}

América Latina y Organización de Cooperación y Desarrollo Económicos (OCDE): evolución de la participación de la masa salarial en el PIB, 1950-2014

(En porcentajes)

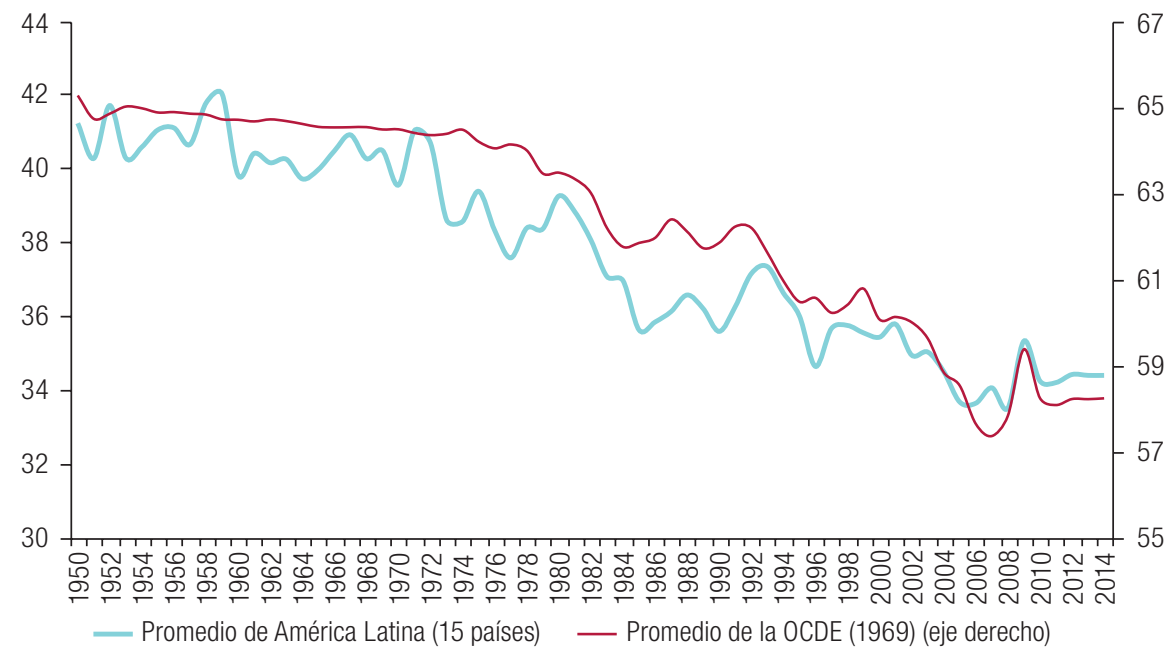

Fuente: Elaboración propia, sobre la base de G. Alarco, "Participación salarial y crecimiento económico en América Latina, 19502011”, Revista CEPAL, № 113 (LC/G.2614-P), Santiago, Comisión Económica para América Latina y el Caribe (CEPAL), 2014, y Universidad de Groningen, Penn World Table [base de datos en línea] https:/www.rug.nl/ggdc/productivity/pwt/.

\section{Ampliación de la brecha externa}

En este contexto, América Latina y el Caribe no cierra la brecha de productividad externa con el mundo desarrollado. En los gráficos 11A y 11B se muestra cómo desde 1990 en adelante el PIB per cápita tanto de América Latina como del Caribe relativo al de la OCDE y los Estados Unidos, si bien comienza a aumentar, después de la década perdida de 1980, no alcanza las magnitudes del período 1950-1989. De forma coherente con lo señalado en el apartado 1 de esta sección, durante la década de 2010 la brecha vuelve a abrirse con respecto a las economías desarrolladas.

\section{Gráfico 11}

América Latina y el Caribe: divergencia productiva expresada como PIB per cápita respecto del PIB per cápita de la Organización de Cooperación y Desarrollo Económicos (OCDE) y de los Estados Unidos, 1900-2018

(En porcentajes)

\section{A. Brecha respecto de la OCDE}

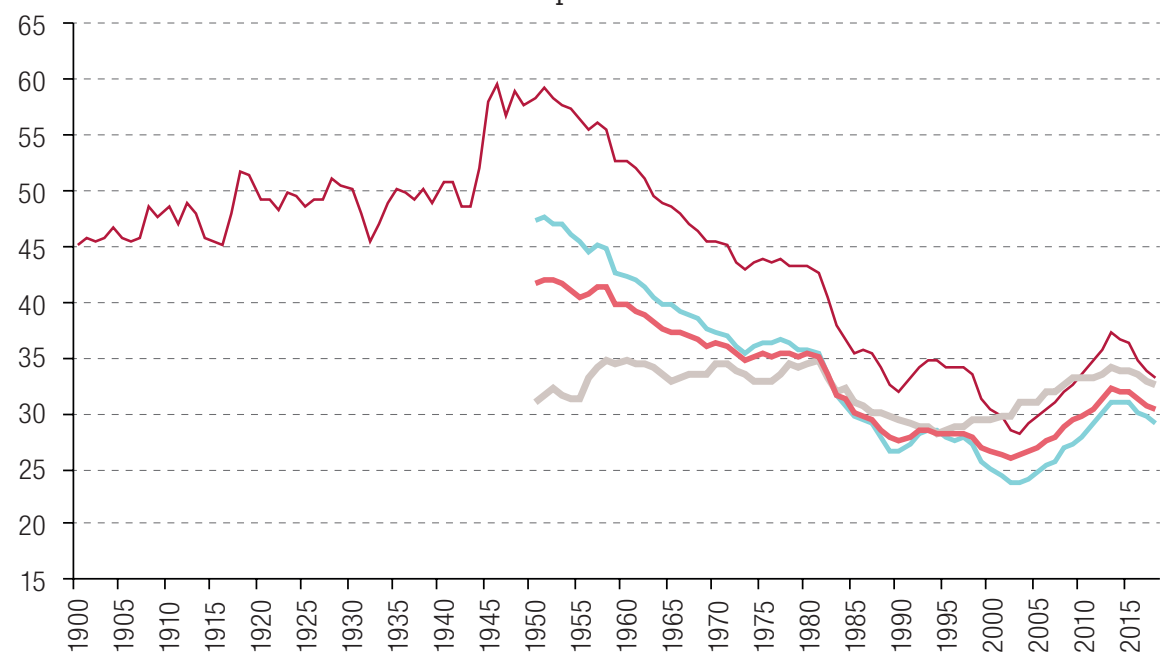




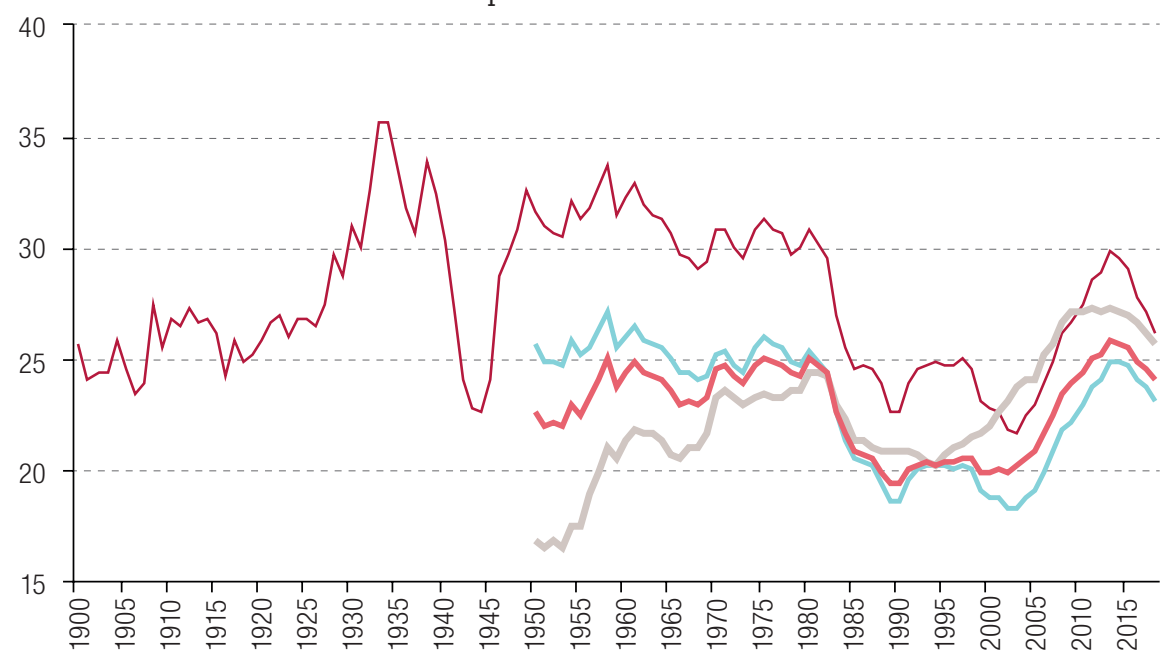

— América Latina (10 países) ${ }^{\mathrm{b}}$ — América Latina (17 países) ${ }^{\mathrm{c}}$ —El Caribe $\left(9\right.$ países) ${ }^{\mathrm{d}}$ — América Latina y el Caribe $\left(26\right.$ países) ${ }^{\mathrm{e}}$

Fuente: Universidad de Groningen, Penn World Table [base de datos en línea] https://www.rug.nl/ggdc/productivity/pwt/.

a Para la brecha con la OCDE, desde 1900 a 1949 se utilizan los datos de 20 países. Desde 1950 son 24 países (países miembros hasta 1973).

b Argentina, Bolivia (Estado Plurinacional de), Brasil, Chile, Colombia, Ecuador, México, Perú, Uruguay y Venezuela (República Bolivariana de).

c Argentina, Bolivia (Estado Plurinacional de), Brasil, Chile, Colombia, Costa Rica, Ecuador, El Salvador, Guatemala, Honduras, México, Nicaragua, Panamá, Paraguay, Perú, Uruguay y Venezuela (República Bolivariana de).

d Barbados, Cuba, Dominica, Haití, Jamaica, Puerto Rico, República Dominicana, Santa Lucía y Trinidad y Tabago.

e Argentina, Barbados, Bolivia (Estado Plurinacional de), Brasil, Chile, Colombia, Costa Rica, Cuba, Dominica, Ecuador, El Salvador, Guatemala, Haití, Honduras, Jamaica, México, Nicaragua, Panamá, Paraguay, Perú, Puerto Rico, República Dominicana, Santa Lucía, Trinidad y Tabago, Uruguay y Venezuela (República Bolivariana de).

\section{Las tres brechas}

De acuerdo con lo señalado en la sección anterior, la pandemia emerge en la región en el marco de tres crisis estructurales: una crisis social que se refleja en los altos niveles de desigualdad; una crisis económica que se refleja en el bajo crecimiento y el rezago tecnológico de la región frente a los países avanzados y (cada vez más) frente a algunas economías asiáticas, y una crisis ambiental que se refleja en la pérdida de biodiversidad, bosques y aguas, y en la tendencia al aumento de las emisiones de gases de efecto invernadero. Estas tres crisis y las políticas necesarias para superarlas interactúan entre sí. Cambiar el estilo de desarrollo de la región exige actuar coordinadamente sobre las tres. La CEPAL (2020i) ha propuesto un modelo de tres brechas que aborda de forma integrada las interacciones entre las variables relevantes y los instrumentos de política. El modelo se construye a partir de tres tasas de crecimiento que se explican a continuación.

\section{La tasa de crecimiento con equilibrio externo, $y^{E}$}

Se entiende que esta es la tasa compatible con el equilibrio de la balanza básica (cuenta corriente y movimientos de capital de largo plazo) de la balanza de pagos. Por razones de simplicidad se usará, para describir el crecimiento con restricción externa, la ecuación de crecimiento con equilibrio en la balanza comercial conocida como Ley de Thirlwall, ya discutida en el apartado 2 de la sección III: 


$$
y^{E}=\frac{\varepsilon y^{C}}{\pi}
$$

En esta expresión, $y^{E}$ es la tasa de crecimiento de la periferia para la cual el saldo neto de la balanza comercial es cero ${ }^{6}$. La ecuación (1) define la curva de equilibrio externo $E E$ (representada en el diagrama 1), que representa todas las combinaciones de $y^{E}$ y de $y^{C}$ que satisfacen el equilibrio en la balanza comercial.

\section{La tasa mínima para reducir la desigualdad, $y^{S}$}

Esta es la tasa requerida, por un lado, para reducir la heterogeneidad estructural, incorporando a los trabajadores en situación de desempleo y subempleo en empleos formales de productividad creciente y, por otro lado, para financiar las políticas sociales y de transferencias de ingresos desde los deciles de ingreso más altos a los más bajos. Si bien parte importante de la reducción de la desigualdad puede lograrse con políticas puramente redistributivas, la creación de empleos formales - lograda por medio del crecimiento y la diversificación productiva - son un complemento necesario de aquellas políticas.

\section{La tasa máxima compatible con la restricción ambiental, $\mathrm{y}^{\mathrm{A}}$}

Esta es la tasa compatible con el respeto de los límites del planeta y su protección para el desarrollo de las futuras generaciones. Desde un punto de vista operacional, puede medirse en términos de metas de reducción de emisiones de gases de efecto invernadero, aunque conceptualmente considera los diversos impactos ambientales de la actividad humana, y no solo el cambio climático. Esa tasa cae con el crecimiento del centro, porque este último deja menos espacio para las emisiones de la periferia, dado un presupuesto total de carbono que debe ser distribuido entre las dos regiones. La frontera ambiental centro-periferia representa todas las combinaciones de crecimiento de la periferia y del centro compatibles con el presupuesto de carbono existente, dada la tasa de descarbonización asociada a las innovaciones ambientales y su difusión hacia el sistema económico global. El progreso técnico orientado a la descarbonización de la producción permitiría reducir las emisiones por unidad de PIB y elevar $y^{A}$ para cada tasa de crecimiento del centro. En la medida en que se utilicen energías más limpias y aumente la eficiencia energética, el mismo presupuesto de carbono será compatible con un crecimiento mayor.

\section{La interacción de las tres tasas}

En la tasa $y^{A}$ se entrecruzan dos dimensiones de la igualdad: i) entre generaciones, ya que toma en cuenta el derecho de las generaciones futuras de disponer de los mismos servicios ambientales para su desarrollo que la generación actual; ii) en la actual generación, ya que considera el derecho de los países más pobres (y de los más pobres en cada país) de mejorar sus niveles de ingreso y bienestar a mayor velocidad que los países más ricos (y que los más ricos en cada país).

\footnotetext{
6 Véanse más detalles en Blecker y Setterfield (2019), capítulo 9.
} 


\section{Diagrama 1}

Las tres brechas del desarrollo sostenible

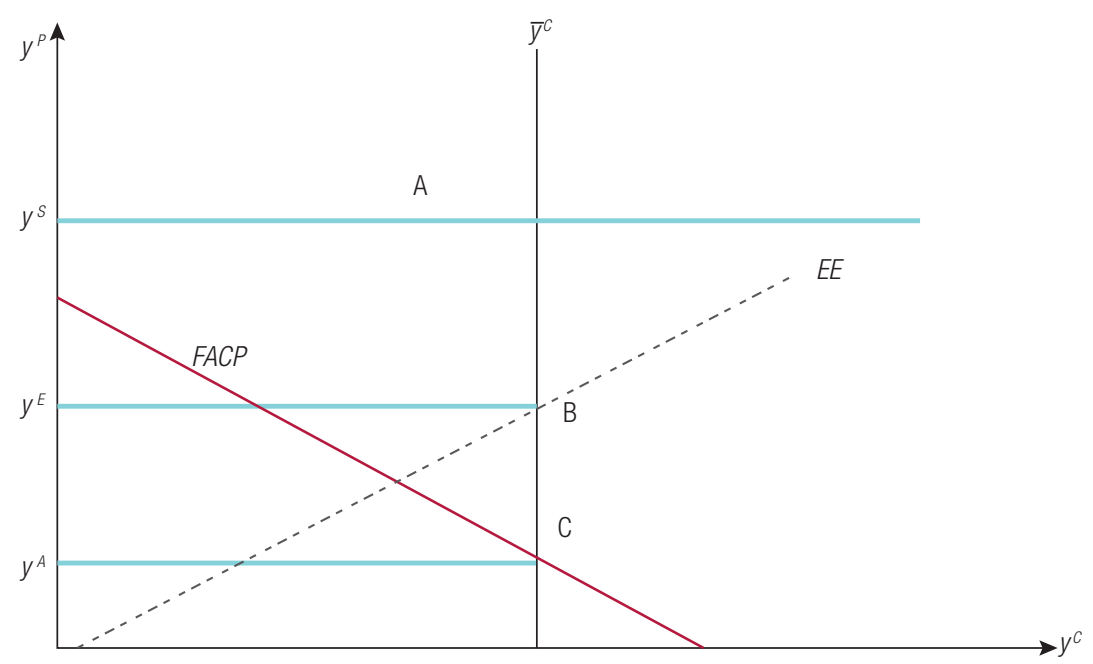

Fuente: Comisión Económica para América Latina y el Caribe (CEPAL).

\section{Nota:}

$y^{P}$ : tasa de crecimiento de la periferia.

$y^{C}$ : tasa de crecimiento del centro (exógena e igual a $\bar{y}$ ).

$y^{E}$ : tasa de crecimiento de la periferia compatible con la restricción externa, que aumenta con el crecimiento (y la demanda de importaciones) del centro y con el aumento de las capacidades tecnológicas de la periferia (competitividad auténtica).

$y^{S}$ : tasa mínima de crecimiento para la igualdad, que será más alta cuanto mayor sea la desigualdad inicial y menor el esfuerzo redistributivo del país.

$y^{A}$ : tasa máxima de crecimiento de la periferia con equilibrio ambiental global, que cae con el crecimiento del centro y que aumenta con la intensidad del progreso técnico, en particular con la innovación y la difusión de tecnologías ambientales.

Brecha social: distancia entre los puntos A y B.

Brecha ambiental: distancia entre los puntos B y C.

Brecha de sostenibilidad (en sus tres dimensiones): distancia entre los puntos A y C.

$E E$ : tasa de crecimiento de la periferia con equilibrio externo.

FACP: frontera ambiental centro-periferia.

En el diagrama 2 se muestran las tres brechas, suponiendo exógena la tasa de crecimiento del centro $\bar{y}^{C}$ : la brecha social, que es la diferencia entre la tasa de crecimiento para la igualdad y la tasa compatible con el equilibrio externo (diferencia entre $y^{S}$ e $y^{E}$, segmento de A a B); la brecha ambiental, que es la diferencia entre la tasa de equilibrio externo y la frontera de sostenibilidad (diferencia entre $y^{E}$ e $y^{A}$, segmento de B a C), y la brecha de la sostenibilidad, que es la que existe entre la tasa de crecimiento para la igualdad y la de equilibrio ambiental (diferencia entre $y^{S}$ e $y^{E}$, segmento de $\mathrm{A}$ a C).

El desarrollo sostenible en sentido amplio solo se logra cuando $y^{E}=y^{S}=y^{A}$, porque se cumplen las condiciones de sostenibilidad en sus tres dimensiones, la social, la económica y la ambiental. De acuerdo con estimaciones hechas por la CEPAL (2020), en el caso de América Latina y el Caribe se verifica que $y^{S}>y^{E}>y^{A}$.

De las tres tasas, la que tiende a prevalecer en una economía abierta es la tasa de crecimiento con equilibrio externo: crecer por encima de ella exige endeudarse, y hay un límite para el nivel de endeudamiento que un país consigue financiar en el mercado internacional. La economía se moverá en función de las presiones externas hacia $y^{E}$. Para lograr el desarrollo sostenible, es necesario implementar un conjunto de políticas que promuevan la convergencia entre las tasas. Este conjunto de políticas representa un gran impulso para la sostenibilidad, que aumenta la inversión en los distintos sectores de la economía de manera coordinada, de forma que las transformaciones sociales, productivas y tecnológicas se refuercen mutuamente. La tasa a la que debe converger la economía es la tasa de crecimiento para la igualdad, la más alta de las tres: políticas sociales, tecnológicas y ambientales deben combinarse para que las tres tasas se igualen al nivel de $y^{S}$. 
Por un lado, las políticas sociales pueden reducir la tasa mínima necesaria para la igualdad. Esta será menor si el nivel inicial de desigualdad es bajo y si las políticas redistributivas son fuertes. El crecimiento y el aumento del empleo formal siempre serán mecanismos imprescindibles para la reducción de la desigualdad, pero su importancia relativa (por lo menos a corto plazo) será menor en presencia de un Estado de bienestar.

Por otro lado, las políticas industriales y tecnológicas pueden impulsar procesos de difusión de tecnología y cambio estructural en la periferia que eleven la competitividad auténtica (y, con ella, la relación $\varepsilon / \pi$ y la tasa de crecimiento con equilibrio externo, $y^{E}$ ) (véanse Cimoli y Porcile, 2014; Cimoli, Pereima y Porcile, 2019).

Finalmente, la convergencia de $y^{E}$ con $y^{A}$ requiere que el progreso técnico tenga una cierta dirección, a saber, elevar la eficiencia en el uso de la energía, reducir las emisiones de gases de efecto invernadero y promover formas sostenibles de producción. Las políticas de innovación y difusión de tecnología no solo deben apoyar la competitividad auténtica, sino además encauzar la economía en sendas bajas en carbono basadas en el uso de energías renovables.

Para que estos procesos sean viables es necesario explorar las complementariedades entre las políticas. Las políticas de inversión en energías renovables pueden reducir el costo de la energía y favorecer así la competitividad internacional; las políticas de educación y estímulo del consumo sostenible ayudarían a que las innovaciones ambientales fueran también favorables a la competitividad (ya que los bienes ofrecidos responderían a los patrones de demanda emergentes); políticas industriales que estimulen la producción interna de vehículos o partes de vehículos eléctricos reducirían los déficits externos y disminuirían las emisiones; políticas sociales a favor de la salud y la educación universales contribuirían no solo a la igualdad, sino también a la productividad, el aprendizaje tecnológico y la competitividad. En el diagrama 2 se resumen las complementariedades entre las políticas y la necesidad de su coordinación en un gran impulso.

\section{Diagrama 2}

Las políticas a favor de la igualdad favorecen también el progreso técnico

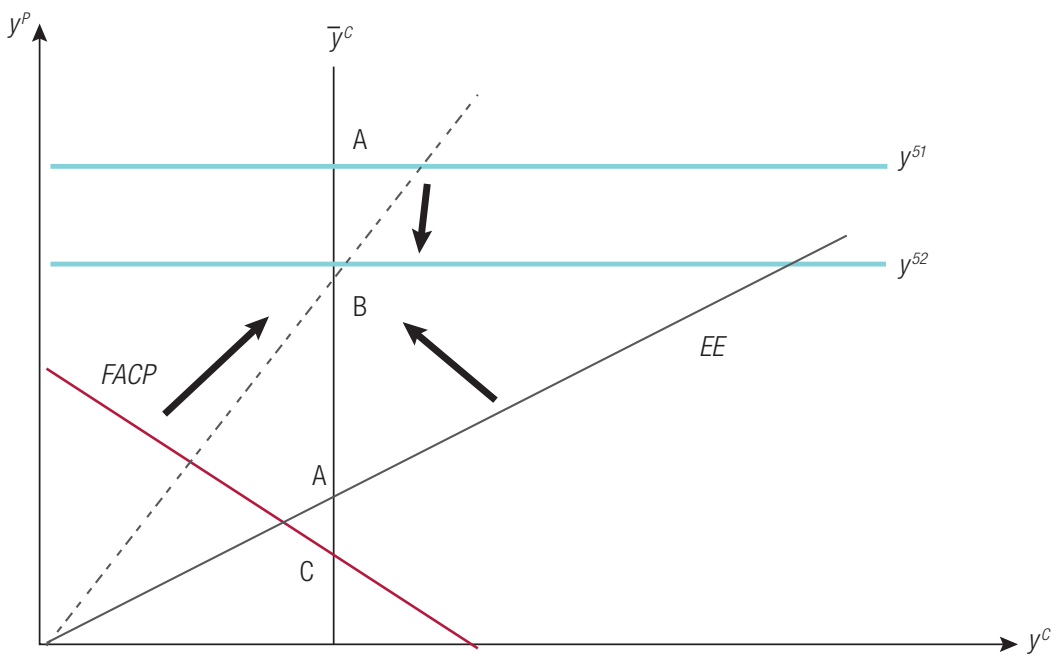

Fuente: Comisión Económica para América Latina y el Caribe (CEPAL).

Nota:

$y^{P}$ : tasa de crecimiento de la periferia.

$y^{C}$ : tasa de crecimiento del centro (exógena e igual a $\bar{y}^{C}$ ).

$y^{s}$ : tasa mínima de crecimiento para la igualdad, que será más alta cuanto mayor sea la desigualdad inicial y menor el esfuerzo redistributivo del país.

Brecha social: distancia entre los puntos $A$ y $B$.

Brecha ambiental: distancia entre los puntos B y C.

Brecha de sostenibilidad (en sus tres dimensiones): distancia entre los puntos A y C.

$E E$ : tasa de crecimiento de la periferia con equilibrio externo.

FACP: frontera ambiental centro-periferia. 
La reducción de la tasa mínima de crecimiento para la igualdad de $y^{S 1}$ a $y^{S 2}$ (del punto A al punto B) sería el resultado de políticas sociales y de bienestar más amplias. Al mismo tiempo, las políticas industriales y tecnológicas moverían la frontera ambiental centro-periferia hacia arriba, elevando la tasa compatible con la protección del medio ambiente, del punto $\mathrm{C}$ al punto $\mathrm{B}$ (entre otros mecanismos, mediante la inversión en energías renovables o en la agricultura y el turismo sostenibles). Los procesos de cambio tecnológico y cambio estructural cambiarían la inclinación de la curva EE (esta inclinación es dada por $\varepsilon / \pi$ ), desplazando la tasa de crecimiento con equilibrio externo del punto $A$ (momento inicial) al punto B (después del cambio del patrón de especialización). Es clave que los instrumentos de política actúen coordinadamente sobre las tres curvas.

\section{Efectos económicos y sociales durante la pandemia}

La pandemia afectó fuertemente la oferta y la demanda agregadas en la región. La intensidad y la persistencia de sus efectos estarán directamente relacionadas con las condiciones internas de cada una de las economías, la dinámica del comercio mundial y la duración de la crisis sanitaria, así como con las políticas sanitarias, económicas y sociales adoptadas para mitigar los impactos de la crisis.

En este sentido, la CEPAL (2020a) clasifica los costos de la pandemia según sus efectos directos en los sistemas de salud y sus efectos indirectos en la producción y el consumo. En cuanto a los efectos directos, se deberán considerar mayores presiones sobre los servicios sanitarios regionales, cuya principal característica es el grado de fragmentación que presentan. La desigualdad de acceso a estas prestaciones se verá intensificada según los niveles de ingreso y el lugar de residencia de los afectados. En cuanto a los efectos indirectos sobre la oferta y la demanda agregadas, las medidas de confinamiento y distanciamiento físico han incidido en la suspensión de actividades productivas, lo que ha afectado los sectores de educación, comercio, turismo, transporte y de extracción de recursos naturales.

\section{Efectos económicos ${ }^{7}$}

\section{a) Magnitud de la crisis en términos macroeconómicos}

A corto plazo se espera que la crisis provoque un incremento de la desocupación, una reducción de los salarios y los ingresos, y aumentos de la pobreza, la pobreza extrema y la desigualdad. A mediano y largo plazo, las mayores consecuencias serían la quiebra de empresas, la reducción de la inversión privada, la disminución de la tasa de crecimiento, una menor integración en cadenas de valor mundiales y un deterioro de las capacidades productivas y de capital humano. La CEPAL ha sostenido que la reactivación económica regional supone una adecuada contextualización y dimensionamiento de los efectos antes señalados. Situando la crisis ocasionada por la pandemia de COVID-19 en una perspectiva histórica, los efectos de corto, mediano y largo plazo serán de tal magnitud, que según la CEPAL (2020b y 2020h) esta crisis es la más profunda desde los años posteriores a la Segunda Guerra Mundial (véase el gráfico 12).

7 Véase un análisis complementario de este tópico en Bárcena (2020). 


\section{Gráfico 12}

América Latina y el Caribe: evolución de la tasa de crecimiento del PIB real, 1951-2019

(En porcentajes)

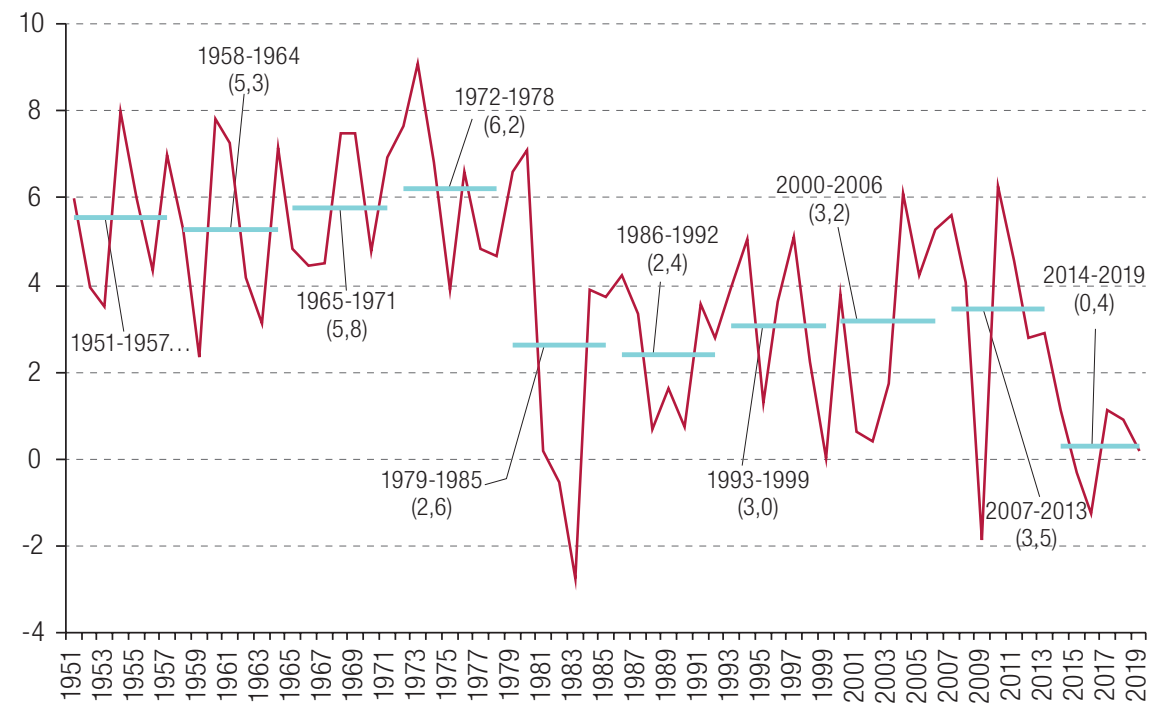

Fuente: Comisión Económica para América Latina y el Caribe (CEPAL), sobre la base de cifras oficiales.

Sobre la base de cálculos de la CEPAL, según los cuales se estima que el PIB per cápita regional caerá un 8,5\%, se prevé un retroceso de esta variable a un nivel similar al de 2010. Esto significa que, como consecuencia de la pandemia y el contexto recesivo anterior, se configurará una nueva década perdida.

En el contexto de este fuerte retroceso, los tejidos productivos perderán densidad, lo que intensificará el problema de la heterogeneidad estructural. Concretamente, se estima que la pandemia ocasionará el cierre de 2,7 millones de empresas formales en la región (CEPAL, 2020d). En concordancia con lo anterior, el desempleo alcanzaría a 44 millones de millones de personas, es decir, 18 millones más que en 2019. Se trata entonces del mayor aumento desde la crisis financiera mundial. Durante ese ciclo recesivo la tasa de desocupación se incrementó del 6,7\% en 2008 al 7,3\% en 2009. De acuerdo con los indicadores presentados en el cuadro 4, la tasa de desocupación interanual representará un 13,5\% de la población económicamente activa (PEA) (CEPAL, 2020e y 2020h).

\section{Cuadro 4}

América Latina y el Caribe: indicadores laborales, 2020

(En millones de personas y porcentajes)

\begin{tabular}{lc}
\hline Indicador & 2020 \\
\hline Población económicamente activa (PEA) & 326,9 \\
\hline Número de desocupados & 44,1 \\
\hline Variación del número de desocupados & 18,0 \\
\hline Tasa de desocupación (porcentaje) & 13,5 \\
\hline
\end{tabular}

Fuente: Comisión Económica para América Latina y el Caribe (CEPAL), sobre la base de cifras oficiales.

a Proyecciones. 
Por otro lado, se deben considerar los efectos adversos de la crisis en la demanda agregada. La CEPAL (2020h) estima que se producirán contracciones de sus principales componentes (la inversión, el consumo y las exportaciones). Las caídas que afectarán a estos agregados macroeconómicos serán más marcadas que las registradas en la crisis financiera internacional de 2008 y 2009. Así, mientras que la inversión real se contrajo un 11,2\% en 2009, en 2020 presentará una caída de un 20,4\%; el consumo, que se contrajo un $0,2 \%$ en la primera crisis, en 2020 se reducirá un $9,5 \%$, y las exportaciones, que en el período 2008-2009 disminuyeron un 9,1\%, en 2020 se contraerán un 11,5\% (véase el gráfico 13).

Gráfico 13

América Latina y el Caribe: variación interanual de los componentes de la demanda agregada, 2008-2009 y 2019-2020a

(En porcentajes)

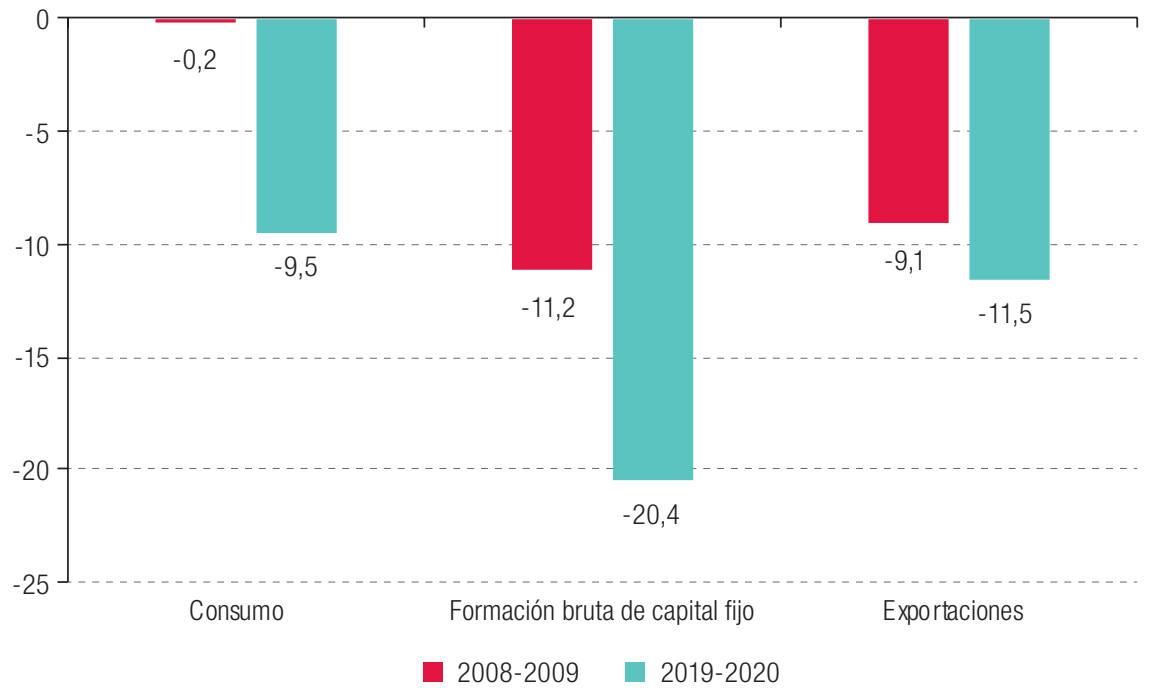

Fuente: Comisión Económica para América Latina y el Caribe (CEPAL), sobre la base de cifras oficiales.

a Proyección.

\section{b) Incidencia de la crisis en el comercio de la región}

Como se señaló anteriormente, la contracción que sufrirá el producto regional se asocia con los efectos externos que ha generado la pandemia, especialmente por la vía del comercio internacional y la caída generalizada de los precios de los productos básicos que exporta la región. De acuerdo con CEPAL (2020f), "la irrupción del COVID-19 se produjo en un contexto de debilitamiento del comercio mundial que se arrastra desde la crisis financiera de 2008-2009". Entre enero y mayo de 2020 la CEPAL ha estimado que el valor de las exportaciones e importaciones de bienes se redujo un 17\% en relación con el mismo período de 2019. Tanto las exportaciones como las importaciones se desplomaron hacia el final de este período de cinco meses y presentaron caídas interanuales del 37\% en mayo.

La disminución interanual del volumen del comercio en el período abril-mayo de 2020 fue mucho mayor que en el mismo período de 2009, en el contexto de la crisis financiera mundial: las exportaciones se redujeron un 20\% y las importaciones un 25\% (véase el gráfico 14). En el caso de las exportaciones, ello se debe a un choque tanto de oferta (como consecuencia del cierre parcial de actividades productivas) como de demanda (contracción económica en los principales mercados de destino de la región). En el caso de las importaciones, la disminución se debe principalmente a la profunda recesión por la que atraviesa la región, con una contracción esperada de su producto del 9,1\% (CEPAL, 2020e). 
Gráfico 14

América Latina y el Caribe: variación interanual de las exportaciones e importaciones de bienes, según volumen, precio y valor, enero de 2007 a mayo de 2020

(En porcentajes)

A. Exportaciones

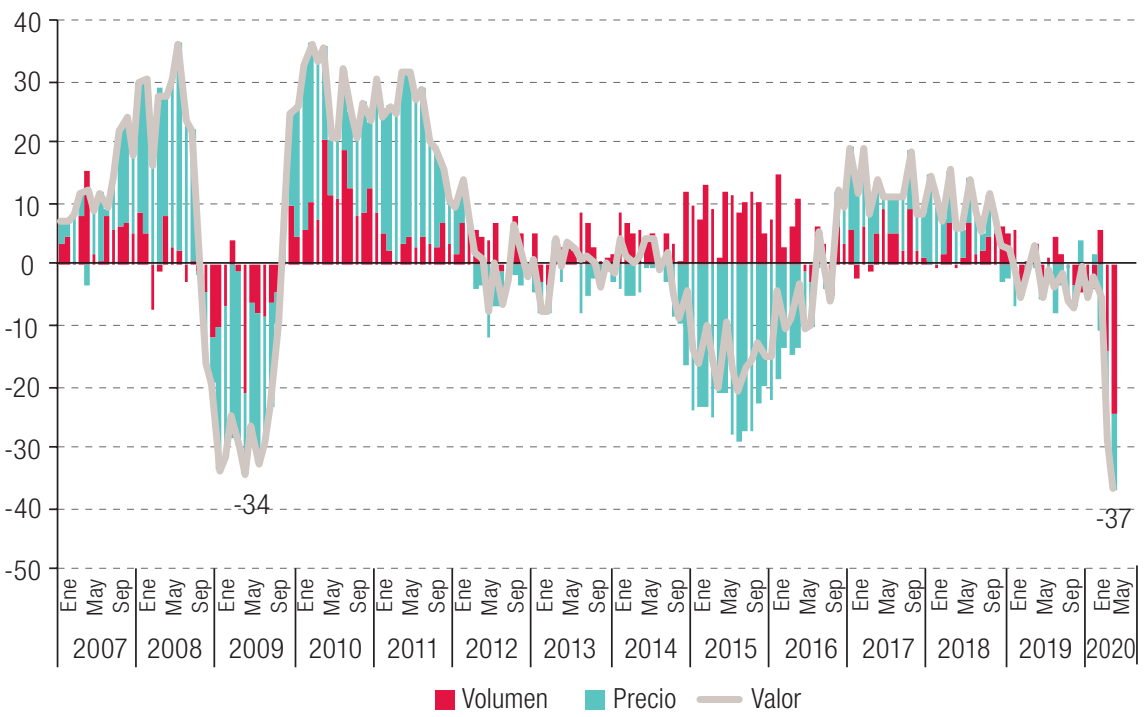

B. Importaciones

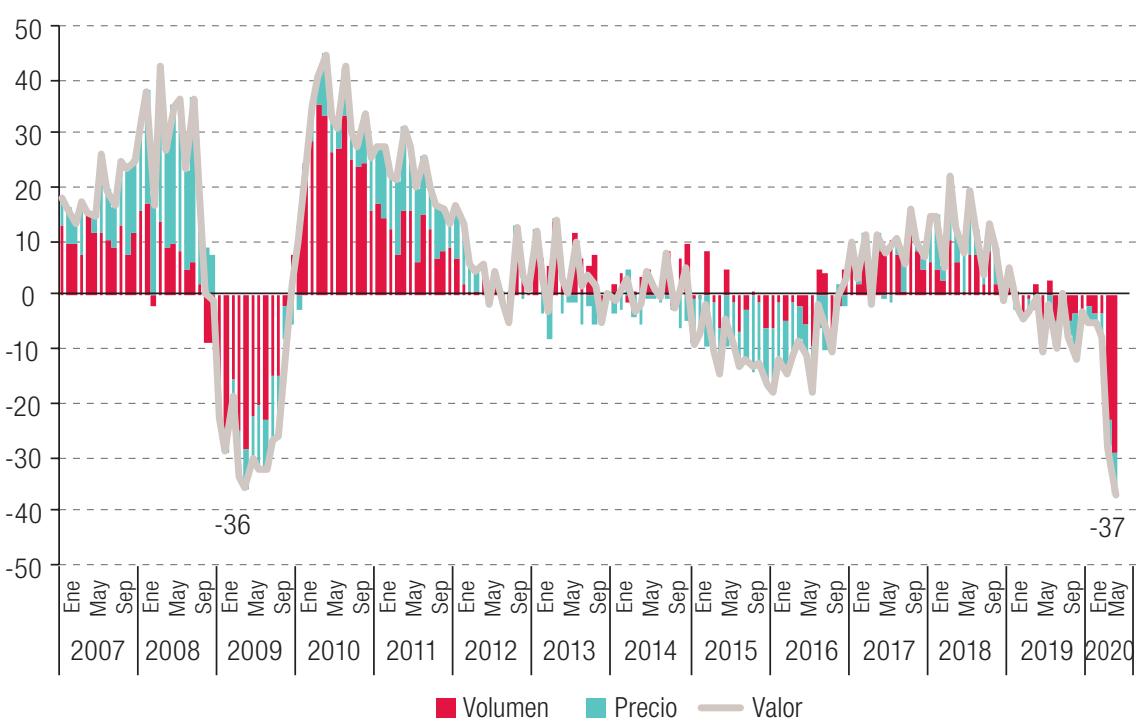

Fuente: Comisión Económica para América Latina y el Caribe (CEPAL), sobre la base de información de los bancos centrales, servicios de aduanas e institutos de estadística de los países.

\section{c) Efectos de la crisis en el desarrollo productivo y el tejido empresarial}

En CEPAL (2020d) se clasifican las ramas de actividad productiva en función de la intensidad de los efectos de la crisis en el producto y el empleo del siguiente modo: i) sectores fuertemente afectados: servicios turísticos, industria cultural tradicional, comercio, reparación de bienes, hoteles y restaurantes, transporte, moda y automóviles; ii) sectores afectados de forma significativa: minería; electricidad, gas y 
agua; construcción y materiales para la construcción; servicios empresariales; actividades financieras; bebidas; muebles y madera; industria química, y electrónica, maquinaria y equipo, y iii) sectores afectados de forma moderada: agricultura, ganadería y pesca; producción de alimentos para el mercado interno; insumos y equipamiento médico; medicamentos; telecomunicaciones, y envases. Sobre esta base, se estima que un $34,2 \%$ del empleo formal y un $24,6 \%$ del PIB de la región corresponden a sectores fuertemente afectados por la crisis derivada de la pandemia. A su vez, proporciones inferiores al $20 \%$ del empleo formal y del PIB se generan en sectores que se verían afectados moderadamente. Por último, un $61,3 \%$ del PIB y un 47,6\% del empleo formal son generados en sectores afectados de forma significativa (véase el gráfico 15).

Del total de empresas que cerrarían, se estima que el impacto será mucho mayor en el caso de las micro, pequeñas y medianas empresas (mipymes), dado el peso que tienen tanto en términos de producción como de empleo. Sobre la base de diagnósticos de las distintas cámaras empresariales de la región, se calcula que 2.650.528 microempresas cerrarían como consecuencia de la crisis sanitaria (un 20,7\% del total), mientras que lo mismo ocurriría con 98.708 empresas pequeñas (7,1\%), 5.943 empresas medianas (2,8\%) y 406 empresas grandes (0,6\%) (CEPAL, 2020d). En cuanto a la pérdida de puestos de trabajo por el cierre de empresas, en el sector de las microempresas podrían perderse 6.383.958 empleos (21,5\% del total), en las empresas pequeñas 1.512 .655 empleos $(7,3 \%)$, en las medianas 390.155 empleos $(2,7 \%)$ y en las grandes empresas 231.724 empleos $(0,6 \%)$.

\section{Gráfico 15}

América Latina y el Caribe (27 países): PIB y empleo correspondientes a los distintos sectores según intensidad del impacto esperado de la crisis, 2020

(En porcentajes)

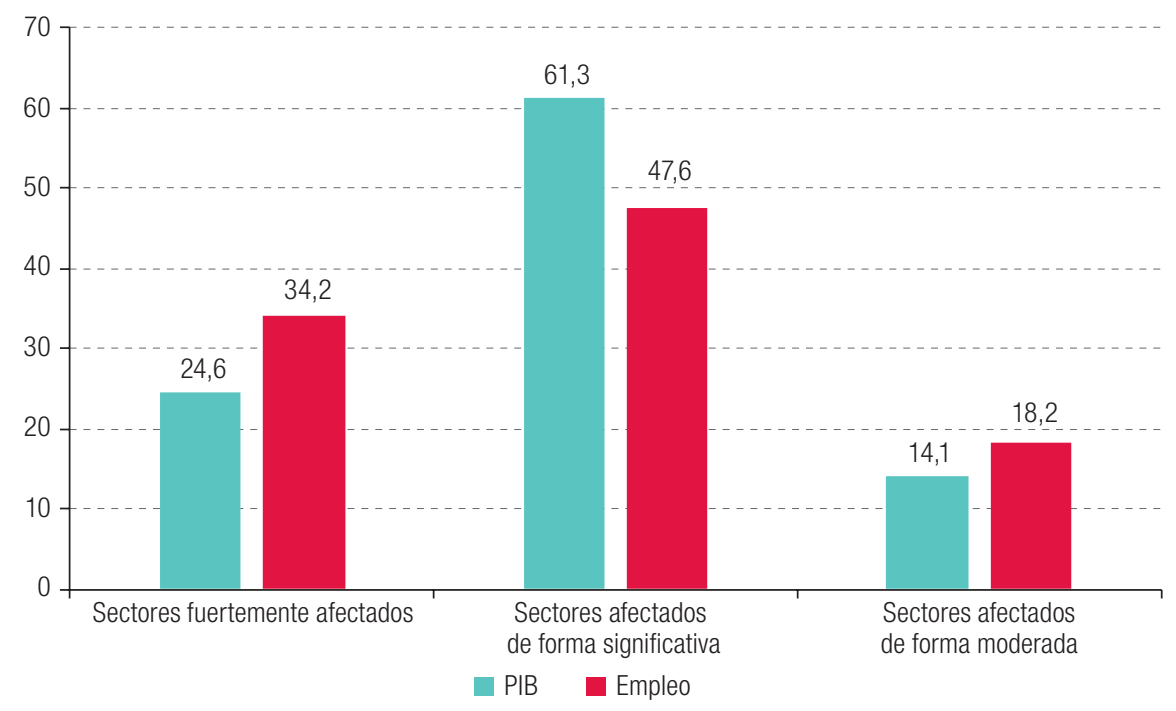

Fuente: Comisión Económica para América Latina y el Caribe (CEPAL), sobre la base de información oficial.

Finalmente, conforme lo señalado en CEPAL (2020g), el sector de la economía digital ha compensado en parte los efectos adversos observados en la economía real y financiera. En efecto, las soluciones en las áreas de la salud, la educación, el comercio y el trabajo a través de aplicaciones orientadas a las comunicaciones a distancia han cumplido un papel en extremo relevante en la lucha por contener los efectos sanitarios y económicos del COVID-19. No obstante, en este estudio también se advierte que la brecha digital puede ampliarse debido a la mayor presión que ha experimentado la demanda de ancho de banda, siendo los sectores sociales más excluidos de estos servicios los grupos de menores ingresos, los grupos etarios de cohortes más antiguas y los residentes de áreas rurales. 


\section{Efectos sociales}

Los efectos económicos analizados en el apartado anterior tendrán repercusiones en el ámbito social. Se prevén retrocesos en relación con los logros que había alcanzado la región en los decenios de 2000 y 2010 en materia de reducción de la pobreza y la desigualdad.

\section{a) Pobreza y pobreza extrema}

Como consecuencia de la pandemia, la región retrocederá a los niveles de hace una década y media en materia de pobreza. De acuerdo con estimaciones de la CEPAL, basadas en cifras de las encuestas de hogares, la población latinoamericana en situación de pobreza en 2020 volvería a los niveles de 2005, esto es, 231 millones de personas. La pobreza extrema, por otra parte, llegaría a 96 millones de personas, un nivel comparable con el que registró la región en 1990. En términos porcentuales, la pobreza en la región aumentará 7,0 puntos porcentuales respecto de la que se registró en 2019 y la pobreza extrema se incrementará en 4,4 puntos porcentuales (véase el gráfico 16).

\section{Gráfico 16}

América Latina (18 países): proyección de la población en situación de pobreza, 2019 y 2020

(En porcentajes)

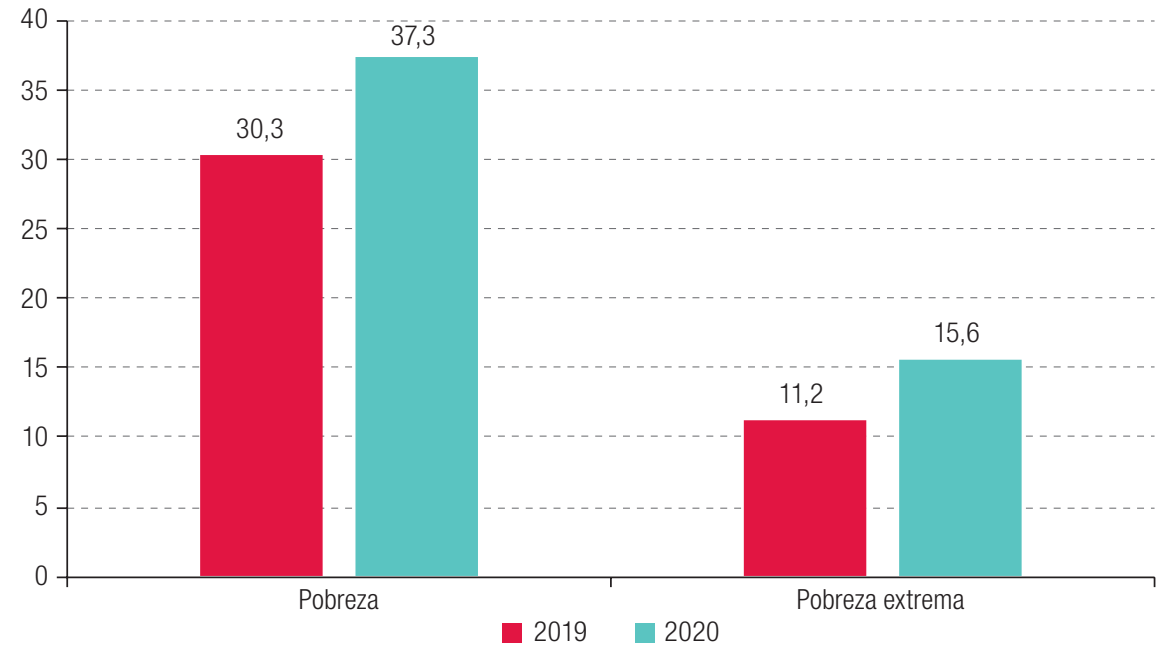

Fuente: Comisión Económica para América Latina y el Caribe (CEPAL), sobre la base de Banco de Datos de Encuestas de Hogares (BADEHOG).

\section{b) Efectos sobre la distribución del ingreso}

De acuerdo con CEPAL (2020c), la pandemia ocasionará retrocesos en materia de distribución del ingreso en todos los países de América Latina. Ello se explica por las pérdidas de empleos y masa salarial examinadas antes. En el gráfico 17 se puede observar con claridad el deterioro distributivo que exhibió la región en el sexenio 2014-2019 en comparación con el ciclo de auge de precios de los productos básicos (2003-2014). En este último período, en virtud del crecimiento económico (especialmente de América del Sur), los gobiernos pudieron aumentar el gasto social orientado a mitigar la pobreza, al mismo tiempo que los niveles de ocupación en las empresas aumentaron, lo que se tradujo en una reducción de la informalidad laboral e incrementos de los ingresos laborales, redundando así en mejoras distributivas que, aunque incipientes, resultaron muy relevantes para muchos países. El fin del ciclo de auge de los productos básicos, a partir de 2014, revirtió todos estos progresos socioeconómicos, en un contexto de menor demanda de materias primas y una fuerte reprimarización 
de la matriz productiva, que provocó una intensificación de la heterogeneidad estructural, llevando a la región a regresiones distributivas.

En el cuadro 5 se muestran los aumentos del coeficiente de Gini proyectados para 2020, según rangos de variación porcentual. Los aumentos, como se dijo, son generalizados y presentan una alta variabilidad de acuerdo con la situación particular de cada país. Guatemala, Nicaragua y el Paraguay tendrán incrementos de entre el 1,0\% y el 2,9\%, mientras que países como Bolivia (Estado Plurinacional de), Costa Rica, Panamá y la República Dominicana verán aumentado su coeficiente de Gini entre un 3,0\% y un 4,9\%. En un rango de variaciones más elevadas, de entre un 5,0\% y un 6,9\%, se encuentran la mayoría de los países de la región: Brasil, Chile, Colombia, El Salvador, México y Uruguay. La Argentina, el Ecuador y el Perú serán los países con mayores retrocesos distributivos, con incrementos del coeficiente de Gini superiores al 7,0\%.

\section{Gráfico 17}

América Latina (17 países): dinámica de la distribución personal del ingreso, 2003-2014 y 2014-2019

(Coeficiente de Gini, rango 0-1)

\section{A. $2003-2014$}

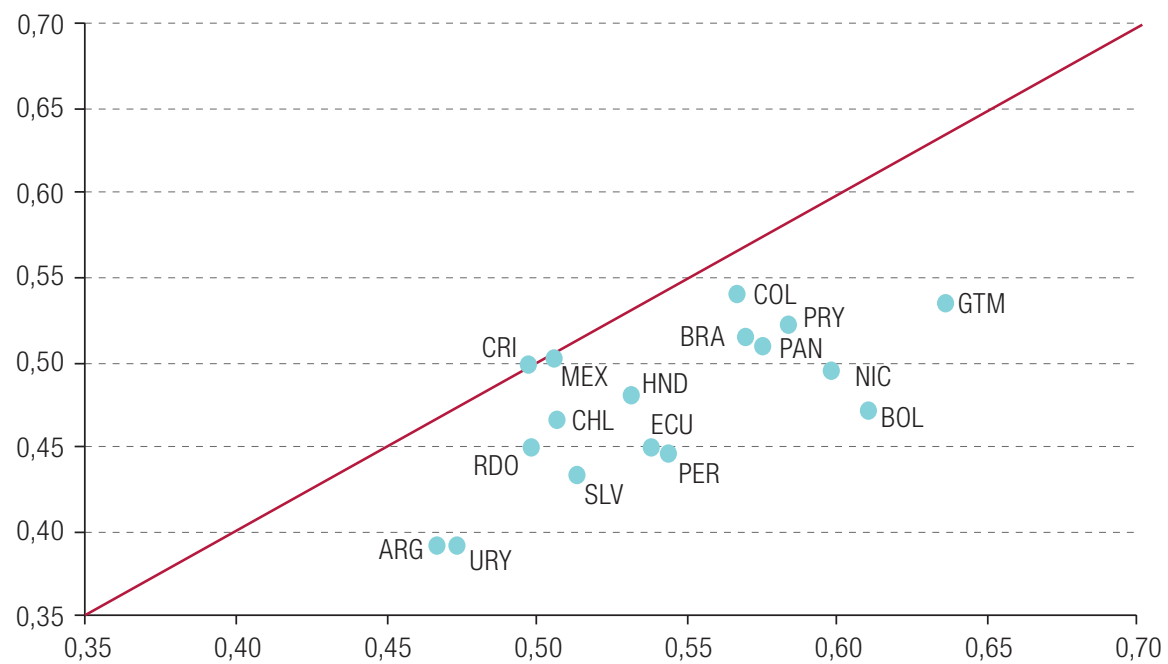

B. 2014-2019

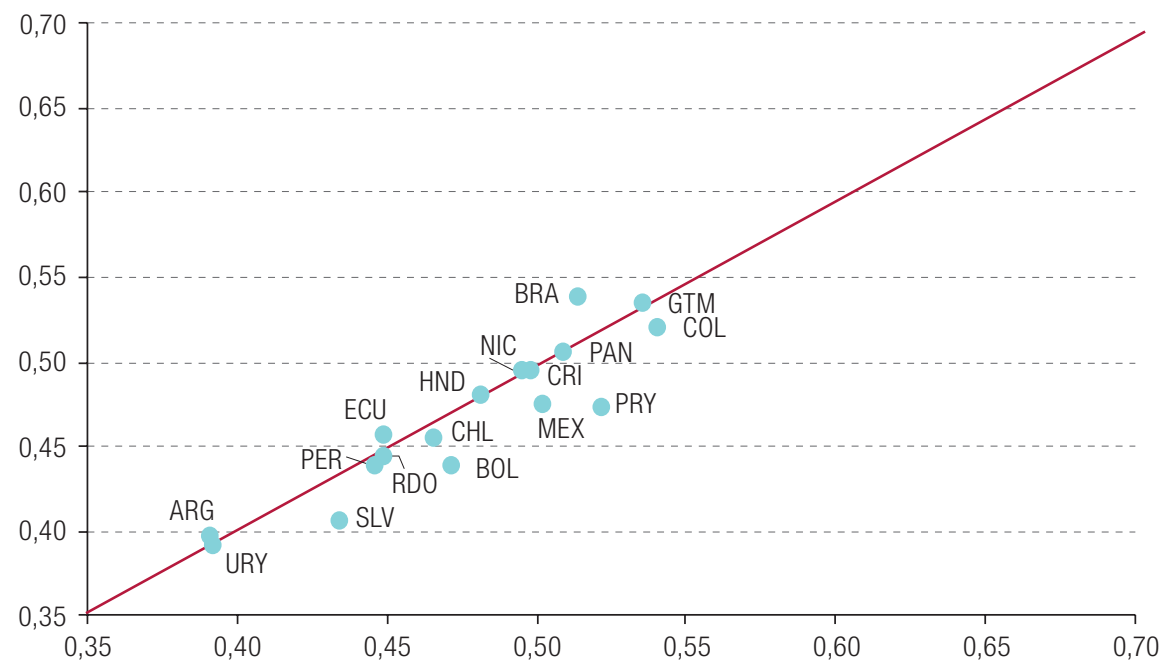

Fuente: Elaboración propia, sobre la base de Comisión Económica para América Latina y el Caribe (CEPAL), Banco de Datos de Encuestas de Hogares (BADEHOG). 
Cuadro 5

América Latina (17 países): incremento del coeficiente de Gini proyectado para 2020

(Rangos de variación porcentual con respecto a 2019)

\begin{tabular}{cccc}
\hline $1,0 \%$ a $2,9 \%$ & $3,0 \%$ a $4,9 \%$ & $5,0 \%$ a $6,9 \%$ & Más de $7,0 \%$ \\
\hline Guatemala & Bolivia (Estado Plurinacional de) & Brasil & Argentina \\
\hline Honduras & Costa Rica & Chile & Ecuador \\
\hline Nicaragua & Panamá & Colombia & Perú \\
\hline Paraguay & República Dominicana & El Salvador & \\
\hline & & México & \\
\hline & & Uruguay & \\
\hline
\end{tabular}

Fuente: Elaboración propia, sobre la base de Comisión Económica para América Latina y el Caribe (CEPAL), Banco de Datos de Encuestas de Hogares (BADEHOG).

Finalmente, es importante consignar que la crisis sanitaria tendrá efectos diferenciados en diversos segmentos de población. Como ha afirmado la CEPAL: "Los diferentes impactos socioeconómicos reflejan la matriz de la desigualdad social en la región, cuyos ejes estructurantes son la pertenencia a distintos estratos socioeconómicos o clases sociales, el género, la etapa del ciclo de vida, la condición étnico-racial y el territorio, a lo que se suman otros factores como la condición de discapacidad, el estatus migratorio o la situación de calle. Estas desigualdades se acumulan, se potencian e interactúan entre sí, causando múltiples discriminaciones que conllevan diferencias en el ejercicio de los derechos" (2020c, pág. 5).

\section{Reflexiones finales: desde la crisis hacia un nuevo estilo de desarrollo}

En este artículo se ha analizado la situación de América Latina y el Caribe en el contexto de la crisis sanitaria impuesta por el COVID-19. Se ha mostrado que la región ha sido la más afectada por la pandemia en términos sanitarios y socioeconómicos. Se ha argumentado que estos resultados se relacionan directamente con la situación que caracterizaba a la región antes de la pandemia. El patrón de especialización, trayectorias divergentes de productividad y absorción de empleo, y el deterioro de la distribución funcional del ingreso asociado a desigualdades más amplias y diversas son asimetrías estructurales que explican la intensidad de la crisis.

Por otro lado, el análisis de los efectos económicos y sociales de la pandemia en la región pone en evidencia el enorme desafío en materia de políticas macroeconómicas, sociales y productivas que deberán desplegarse para llevar adelante un proceso de reactivación poscrisis. La CEPAL ha planteado que dicha recuperación debe ir simbióticamente acompañada de una transformación estructural orientada a cerrar las tres brechas que caracterizan el disfuncional modelo económico vigente. A esta estrategia la CEPAL la ha calificado como una recuperación transformadora para el desarrollo sostenible, es decir, una estrategia que combine la recuperación económica con la superación del estilo de desarrollo vigente (CEPAL, 2020i).

En relación con los aspectos contingentes de la pandemia, la CEPAL ha planteado cuatro líneas de acción. En primer lugar, se propone otorgar un ingreso básico de emergencia como instrumento de protección social. En segundo lugar, se plantea la entrega de un bono contra el hambre. En tercer lugar, se proponen un conjunto de políticas orientadas a apoyar los tejidos empresariales y los segmentos laborales en riesgo de engrosar las listas de desempleados. Finalmente, se propone también fortalecer el rol de las instituciones financieras internacionales para hacer frente a los requerimientos de financiamiento a nivel mundial. 
En una perspectiva de mediano y largo plazo, la CEPAL plantea que el desarrollo sostenible en los ámbitos social, económico y medioambiental no es algo que los mercados no regulados puedan lograr por sí solos. Se requiere poner en marcha políticas públicas en diversas áreas y de manera simultánea en materias de innovación y actualización tecnológica; avanzar hacia un Estado de bienestar para apoyar el aprendizaje y la igualdad; rediseñar los incentivos económicos para fomentar la protección del medio ambiente, y aplicar políticas macroprudenciales que brinden estabilidad y que promuevan la competitividad, políticas fiscales progresivas para la igualdad y el financiamiento de inversiones públicas y políticas sectoriales para fomentar la expansión de los sectores que son los principales impulsores de la sostenibilidad. Estas políticas deben articularse y basarse en posibles complementariedades y sinergias, en una respuesta que la CEPAL ha calificado como un gran impulso para la sostenibilidad.

La dimensión sectorial de estas políticas es crucial. Así, la transición hacia el desarrollo sostenible implicará emprender acciones para viabilizar un proceso que permita incrementar la participación de algunos sectores en el PIB, fomentando sectores estratégicos y desalentando fuertemente otros, ya sea por razones ambientales, de igualdad o tecnológicas.

La CEPAL ha identificado siete sectores estratégicos para el desarrollo sostenible, en términos de competitividad, empleo, igualdad, descarbonización y sostenibilidad ambiental:

- Transición hacia energías renovables no convencionales, para contar con una matriz energética sostenible

- Movilidad sostenible en espacios urbanos

- Economía digital inclusiva e innovadora para el crecimiento y la sostenibilidad

- Industria manufacturera para el cuidado de la salud

- Bioeconomía para un desarrollo sostenible basado en recursos biológicos y ecosistemas naturales

- Economía circular orientada hacia el fomento del reciclaje

- Turismo sostenible

Estas actividades deben estar en el centro de las políticas industriales y tecnológicas. Los incentivos deben alinearse para alentar a estos sectores, con un papel importante de la inversión pública para atraer la inversión privada y mantener la demanda efectiva en el contexto de la crisis.

Finalmente, esta transformación requerirá pactos políticos que incluyan políticas fiscales expansivas, progresivas, eficaces y eficientes. Se requiere de liderazgos que den mayores grados de certidumbre, que sepan construir alianzas, que ayuden a recuperar la política y el bienestar, promover la solidaridad entre las naciones, fortalecer la integración regional, cumplir las agendas internacionales, entre ellas la Agenda 2030 para el Desarrollo Sostenible, y enlazar la emergencia con la recuperación.

\section{Bibliografía}

Abeles, M., E. Pérez Caldentey y G. Porcile (2020), "La crisis del COVID-19 y los problemas estructurales de América Latina y el Caribe: responder a la urgencia con una perspectiva de largo plazo", Revista CEPAL, № 132, edición especial, Santiago, Comisión Económica para América Latina y el Caribe (CEPAL).

Alarco, G. (2014), "Participación salarial y crecimiento económico en América Latina, 1950-2011", Revista CEPAL, № 113 (LC/G.2614-P), Santiago, Comisión Económica para América Latina y el Caribe (CEPAL).

Bárcena, A. (2020), "ALC ante la crisis de la COVID-19: cómo debe ser la reactivación", Revista Pensamiento Iberoamericano: Iberoamérica ante la pandemia, 3ra Época - 01/2020.

Blanchard, O. y L. Summers (1986), "Hysteresis and the European unemployment problem", NBER Macroeconomics Annual, vol. 1, Cambridge, MIT Press. 
Blecker, A. y R. Setterfield (2019), Heterodox Macroeconomics: Models of Demand, Growth and Distribution, Massachusetts, Edward Elgar Publishing.

CEPAL (Comisión Económica para América Latina y el Caribe) (2020a), "América Latina y el Caribe ante la pandemia del COVID-19: efectos económicos y sociales”, Informe Especial COVID-19, № 1, Santiago, abril. (2020b), "Dimensionar los efectos del COVID-19 para pensar en la reactivación", Informe Especial COVID-19, № 2, Santiago, abril.

(2020c), "El desafío social en tiempos del COVID-19", Informe Especial COVID-19, № 3, Santiago, mayo. (2020d), "Sectores y empresas frente al COVID-19: emergencia y reactivación", Informe Especial COVID-19, № 4, Santiago, julio.

(2020e), "Enfrentar los efectos cada vez mayores del COVID-19 para una reactivación con igualdad: nuevas proyecciones", Informe Especial COVID-19, №5, Santiago, julio.

(2020f), "Los efectos del COVID-19 en el comercio internacional y la logística", Informe Especial COVID-19, $N^{\circ} 6$, Santiago, agosto.

- (2020g), "Universalizar el acceso a las tecnologías digitales para enfrentar los efectos del COVID-19", Informe especial COVID-19, № 7, Santiago, 26 de agosto.

(2020h), Estudio Económico de América Latina y el Caribe, 2020 (LC/PUB.2020/12-P), Santiago.

(2020i), Construir un nuevo futuro: una recuperación transformadora con igualdad y sostenibilidad (LC/SES.38/3-P/Rev.1), Santiago.

(2020j), Balance Preliminar de las Economías de América Latina y el Caribe, 2020 (LC/PUB.2020/17-P), Santiago.

Cimoli, M. y G. Porcile (2014), "Technology, structural change and BOP constrained growth: a structuralist toolbox", Cambridge Journal of Economics, vol. 38, № 1.

Cimoli, M., J. B. Pereima y G. Porcile (2019), "A technology gap interpretation of growth paths in Latin America and Asia", Research Policy, vol. 48.

Fajnzylber, F. (1990), “La industrialización en América Latina: de la 'caja negra' al 'casillero vacío'”, Cuaderno de la CEPAL, № 60 (LC/G.1534/Rev.1-P), Santiago, Comisión Económica para América Latina y el Caribe (CEPAL), agosto.

Murillo, G. (2011), "Recordando la gripe española", Medicina Interna de México, vol. 27, № 5, Ciudad de México.

Ocampo, J. A. (2020), "La cooperación financiera internacional frente a la crisis económica latinoamericana", Revista CEPAL, № 131 (LC/PUB.2020/9-P), Santiago, Comisión Económica para América Latina y el Caribe (CEPAL).

Prebisch, R. (1963), Hacia una dinámica del desarrollo latinoamericano, Ciudad de México, Fondo de Cultura Económica.

_ (1962), "El desarrollo económico de la América Latina y algunos de sus principales problemas", Boletín Económico de América Latina, vol. 7, № 1, febrero.

Rodríguez, O. (2006), El estructuralismo latinoamericano, Ciudad de México, Siglo XXI. (1977), "Sobre la concepción del sistema centro-periferia", Revista de la CEPAL, № 3, Santiago, Comisión Económica para América Latina (CEPAL).

Seers, D. (1962), "A Model of comparative rates of growth in the world economy", The Economic Journal, vol. 72, No 285, 1 de marzo.

Setterfield, M. (2009), "Path dependency, hysteresis and macrodynamics", Path Dependency and Macroeconomics, P. Arestis y M. Sawyer (eds.), Londres, Palgrave Macmillan.

Thirlwall, A. (1979), "The balance of payments constraint as an explanation of international growth rate differences", BNL Quarterly Review, vol. 32, № 128, Banca Nazionale del Lavoro.

Torres, M. (2019), "Globalización, capitalismo transnacional y dependencia: el itinerario de una 'visión'”, Del estructuralismo al neoestructuralismo: la travesía intelectual de Osvaldo Sunkel, A. Bárcena y M. Torres (eds.), Santiago, Comisión Económica para América Latina y el Caribe (CEPAL). 